\title{
Residual activity evaluation: a benchmark between ANITA, FISPACT, FLUKA and PHITS codes
}

\author{
Gabriele Firpo ${ }^{1, *}$, Carlo Maria Viberti $^{1}$, Anna Ferrari $^{2}$, Manuela Frisoni $^{3}$ \\ ${ }^{1}$ Ansaldo Nucleare, Corso Perrone 25, Genova, Italy, 16152 \\ ${ }^{2}$ Helmholtz-Zentrum Dresden-Rossendorf e. V., Bautzner Landstraße 400, Dresden, Germany, 01328 \\ ${ }^{3}$ Agenzia Nazionale per le Nuove tecnologie, l'Energia e lo Sviluppo economico sostenibile, Via Martiri Monte Sole 4, Bologna, Italy, \\ 40129
}

\begin{abstract}
The activity of residual nuclides dictates the radiation fields in periodic inspections/repairs (maintenance periods) and dismantling operations (decommissioning phase) of accelerator facilities (i.e., medical, industrial, research) and nuclear reactors. Therefore, the correct prediction of the material activation allows for a more accurate planning of the activities, in line with the ALARA (As Low As Reasonably Achievable) principles. The scope of the present work is to show the results of a comparison between residual total specific activity versus a set of cooling time instants (from zero up to 10 years after irradiation) as obtained by two analytical (FISPACT and ANITA) and two Monte Carlo (FLUKA and PHITS) codes, making use of their default nuclear data libraries. A set of $\sim 40$ irradiating scenarios is considered, i.e. neutron and proton particles of different energies, ranging from zero to many hundreds $\mathrm{MeV}$, impinging on pure elements or materials of standard composition typically used in industrial applications (namely, AISI SS316 and Portland concrete). In some cases, experimental results were also available for a more thorough benchmark.
\end{abstract}

\section{Background and Scope}

The evaluation of the residual nuclide activity in irradiated materials is an important issue in radiological analysis. The activity of residual nuclides dictates the radiation fields in periodic inspections/repairs (maintenance periods) and dismantling operations (decommissioning phase) of accelerator facilities (i.e., medical, industrial, research) and nuclear reactors. Therefore, the correct prediction of the material activation allows for a more accurate planning of the activities, in line with the ALARA (As Low As Reasonably Achievable) principles.

Typically, the irradiation source, impinging on the material during operation, is known in terms of particle type (potentially a combination of neutrons and other hadrons), flux, energy spectrum and time evolution. While the composition of irradiation samples is usually well known, radiation protection practically refers to standard compositions for structural materials; from an engineering point of view, steel and concrete materials are of particular interest in many nuclear applications.

Starting from the characterized source and material composition, the time evolution of the nuclide inventory, and the corresponding residual activity, can be predicted by solving the set of Bateman equations [1].

Nowadays, many analytical and Monte Carlo computer codes include a Bateman solver routine, offering suitable simulation capabilities. The external irradiation source specification, the material composition, the irradiation history and cooling time instants represent the input data set, which is combined with half-life parameters and activation cross sections of nuclides to calculate the isotope inventories.

Different geometrical approaches are followed by the computer codes, depending on the selected methodologies, whether purely analytical (i.e., Bateman equations solver in a so called " 0 -dimensional" approach) or Monte Carlo (i.e., Bateman equations solver integrated in a multi-dimensional radiation transport code). These approaches are synthetically described both here below and in Table 1 .

The "0-dimensional" approach of the analytical codes assumes an homogeneous, isotropic and energydependent flux of the irradiating particle defined in an infinite medium of specified density and isotopic composition.

A fully "3-dimensional" approach is instead implemented in the Monte Carlo codes: the modelled geometry and materials are irradiated by a user defined source; the simulation particles are transported, taking into account any possible interaction with the material nuclides (i.e., absorption, down and up scattering, buildup,...).. The irradiating flux can be averaged in tallied regions (e.g. through track length estimators), and then passed to the Bateman solver routine.

Corresponding author: Gabriele.Firpo@ann.ansaldoenergia.com 
Table 1. Comparison between the " 0 -dimensional" and "3dimensional" approaches for the evaluation of the residual activity or nuclide inventory by computational codes.

\begin{tabular}{|c|c|c|c|}
\hline & 0-dimensional & 3-dimensional \\
\hline \multicolumn{2}{|c|}{$\begin{array}{l}\text { Method of } \\
\text { solution }\end{array}$} & $\begin{array}{l}\text { Solution of the } \\
\text { Bateman } \\
\text { equations }\end{array}$ & $\begin{array}{l}\text { Full Monte Carlo } \\
\text { calculation or } \\
\text { mixed Monte } \\
\text { Carlo and solution }\end{array}$ \\
\hline \multirow{3}{*}{$\begin{array}{l}\text { Parame- } \\
\text { ters of the } \\
\text { Bateman } \\
\text { equations }\end{array}$} & $\begin{array}{l}\text { Initial } \\
\text { material } \\
\text { composi- } \\
\text { tion }\end{array}$ & $\begin{array}{l}\text { Input by user } \\
\text { (infinite medium } \\
\text { assumed, mass } \\
\text { and volume } \\
\text { treated as } \\
\text { normalization } \\
\text { factors) } \\
\end{array}$ & $\begin{array}{l}\text { Input by user (real } \\
\text { geometry } \\
\text { modelled) }\end{array}$ \\
\hline & $\begin{array}{l}\text { Transmu- } \\
\text { tation } \\
\text { cross } \\
\text { section } \\
\end{array}$ & $\begin{array}{l}\text { Evaluated data } \\
\text { libraries }\end{array}$ & $\begin{array}{c}\text { Evaluated data } \\
\text { libraries and/or } \\
\text { models }\end{array}$ \\
\hline & $\begin{array}{l}\text { Irradiating } \\
\text { flux }\end{array}$ & $\begin{array}{l}\text { Input by user } \\
\text { (homogeneous } \\
\text { and isotropic flux } \\
\text { assumed) }\end{array}$ & $\begin{array}{c}\text { Track-length } \\
\text { averaged by } \\
\text { Monte Carlo } \\
\text { calculation } \\
\text { starting from user- } \\
\text { defined real } \\
\text { impinging flux } \\
\text { (more realistic } \\
\text { representation) }\end{array}$ \\
\hline \multicolumn{2}{|c|}{$\begin{array}{l}\text { Graphical } \\
\text { representation }\end{array}$} & तो & $\begin{array}{lll}\pi & \pi & \pi \\
\pi & \pi & \pi \\
\pi & \pi & \pi\end{array}$ \\
\hline \multicolumn{2}{|c|}{ Limitations } & $\begin{array}{l}\text { No build-up*; } \\
\text { No self-shielding } \\
\text { and flux } \\
\text { attenuation* }\end{array}$ & No build-up* \\
\hline
\end{tabular}

The scope of the present work is to show the results of a comparison between residual total specific activity versus a set of cooling time instants (from zero up to 10 years after irradiation) as obtained by two analytical (FISPACT [2] and ANITA [3]) and two Monte Carlo (FLUKA [4][5] and PHITS [6]) codes, making use of their default nuclear data libraries.

\section{Methodology Description}

A set of several tens irradiating scenarios was considered, i.e. neutron and proton particles of known energies, ranging from zero to many hundreds $\mathrm{MeV}$, impinging on a restricted set of defined materials. In many of the considered scenarios, called "calculational case studies", no corresponding experimental results were available, and the benchmark was performed only among the results of the calculations. In some other cases, called "experimental case studies", experimental results were also available for a more thorough benchmark.
In general, the following parameters must be fixed in order to completely set an irradiation scenario:

- The irradiation particle type and intensity;

- The spatial, directional and energy distribution of the irradiation particle;

- The initial material composition of the irradiated sample;

- The sample geometry;

- The irradiation time(s);

- The cooling time instant(s) after irradiation at which the total specific activity has to be evaluated.

Details on how these parameters were fixed, slightly depending both on the case study type and on the analytical or Monte Carlo method of solution, are reported hereafter.

\subsection{The Calculational Case Studies}

In this set of case studies, comparison was made among total specific activity values obtained by analytical (FISPACT and ANITA) and Monte Carlo (FLUKA and PHITS) codes.

\subsubsection{The irradiation geometry and parameters}

First of all, the irradiation geometry and the geometrical model was fixed as simple as possible as shown in Figure 1: the irradiating flux, monochromatic in energy, impinges perpendicularly and uniformly on the basis of a cylindrical sample. It had fixed radius equal to $1 \mathrm{~cm}$ and variable height, being 0.1 or 3 times the irradiating particle mean free path and defining the "thin" and "thick" cases, respectivelya. A set of two typical structural materials used in industrial application, namely the AISI SS316 and the Portland concrete, was chosen; their isotopic compositions and densities were taken from [7].

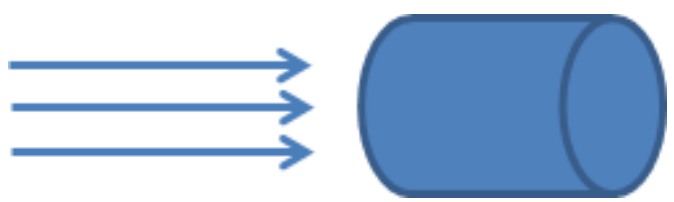

Figure 1. The irradiation geometry considered in the "calculational case studies".

The irradiation parameter values considered in the calculations are summarized in Table 2. Any combination of the irradiation particle energy and type, sample material and sample thickness values defined a different irradiation scenario.

\footnotetext{
${ }^{a}$ The thin and thick cases were defined in order to consider both the scenario where the irradiating energy spectrum and intensity are negligibly or slightly modified in the sample (thin case) and the scenario where they are considerably modified and attenuated in the sample (thick case).
} 
Table 2. List of the irradiation parameter values considered in the present work for the "calculational case studies". Any combination of the values of the highlighted parameters defines a different irradiation scenario; the other parameters remained unchanged for each scenario.

\begin{tabular}{|c|c|}
\hline Parameter & Values \\
\hline \multirow{2}{*}{$\begin{array}{l}\text { Irradiation particle and energy } \\
{[\mathrm{MeV}]}\end{array}$} & Neutron: $2.5 \mathrm{e}-8,50,200$ \\
\hline & Proton: $10,50,600$ \\
\hline \multirow{2}{*}{ Sample material } & Steel (AISI SS316) \\
\hline & Concrete (Portland) \\
\hline \multirow{2}{*}{ Sample thickness (height) } & $\sim \lambda / 10$ (thin case) \\
\hline & $\sim 3 \lambda$ (thick case) \\
\hline Flux intensity [particle $/ \mathrm{cm}^{2} / \mathrm{s}$ ] & $1 \mathrm{e} 10$ \\
\hline Irradiation time & $1 \mathrm{y}$ \\
\hline Cooling time instants & $\begin{array}{c}1 \mathrm{~s}, 1 \mathrm{~h}, 1 \mathrm{~d}, \\
1 \text { week, } 1 \text { month, } \\
6 \text { months, } 1 \mathrm{y}, 5 \mathrm{y}, 10 \mathrm{y}\end{array}$ \\
\hline
\end{tabular}

$* \lambda$ is equal to the mean free path of the irradiating particle as taken from literature or dedicated Monte Carlo evaluation for each material and energy value defined above.

The total number of irradiation scenarios considered for the Calculational case studies was then equal to:

$$
\begin{gathered}
\left(\#_{\text {neutron energies }}\right)\left(\#_{\text {materials }}\right)\left(\#_{\text {thicknesses }}\right)+ \\
\left(\#_{\text {proton energies }}\right)\left(\#_{\text {materials }}\right)\left(\#_{\text {thicknesses }}\right)= \\
3 \cdot 2 \cdot 2+3 \cdot 2 \cdot 2=24
\end{gathered}
$$

\subsubsection{The calculational methodology}

In the Monte Carlo approach with FLUKA and PHITS codes, the calculation of the residual specific activity at the requested cooling time instants starting from the irradiation scenarios beforehand described were performed automatically during the Monte Carlo run via the RESNUCLEI card or via the dedicated post-Monte Carlo processing code "dchain-sp", respectively.

A two-step method was instead necessary for the simulations with the analytical codes FISPACT and ANITA: firstly, the averaged flux (track-length estimation, discerned in few hundreds of logarithmicinterpolated energy bins) in the sample material was evaluated by a radiation transport simulation with a Monte Carlo code, making use of the same irradiation source and geometry of the Monte Carlo approach; secondly, the deterministic calculation was performed with FISPACT and ANITA, defining the track-length averaged particle flux evaluated in the first step as the irradiating flux.

All the Monte Carlo calculations were performed setting an appropriate number of starting particles so that the output results (total activity and track-length estimator values) had a relative error well below $1 \%$ in all the cases.

The information on the code versions and nuclear dataset used in the calculations, as well as the information on the computable scenarios for each code - due to nuclear data availability-, is reported in Table 3 .
Table 3. Code name, version and nuclear dataset (transmutation cross sections) used in the calculations of the "Calculational case studies".

\begin{tabular}{|c|c|c|c|}
\hline $\begin{array}{c}\text { Code } \\
\text { name }\end{array}$ & Version & $\begin{array}{c}\text { Nuclear } \\
\text { dataset }\end{array}$ & $\begin{array}{c}\text { Irradiation } \\
\text { scenarios }\end{array}$ \\
\hline FLUKA & $2011.2 \mathrm{c}$ & Proprietary & $\begin{array}{c}\text { All the scenarios } \\
\text { calculated }\end{array}$ \\
\hline PHITS & 2.82 & JENDL 4.0 & $\begin{array}{c}\text { All the scenarios } \\
\text { calculated }\end{array}$ \\
\hline FISPACT & 2010 & EAF2010 & $\begin{array}{c}\text { All except } 600 \\
\text { MeV protons } \\
\text { and } 200 \mathrm{MeV} \\
\text { neutrons }\end{array}$ \\
\cline { 2 - 4 } & II & TENDL2014 & $\begin{array}{c}\text { Only } 200 \mathrm{MeV} \\
\text { neutrons }\end{array}$ \\
\hline ANITA* & $4 \mathrm{M}$ & EAF2010 & $\begin{array}{c}\text { Only 2.5e-8 } \\
\text { MeV neutrons }\end{array}$ \\
\hline
\end{tabular}

\subsection{The Experimental Case Studies}

In this set of case studies, comparison was made among total specific activity values following neutron irradiation obtained by analytical codes (FISPACT and ANITA), Monte Carlo codes (FLUKA and PHITS) and experimental data taken from activity measurements performed at the Karlsruhe Isochronous Cyclotron ("IFMIF cases" in the following [8]) and at the Frascati Neutron Generator ("FNG cases" in the following [9]).

\subsubsection{The irradiation geometry and parameters}

The irradiation parameters, materials and geometry were defined referring to the experimental specification reported in [8] and [9]. The irradiating neutron spectra on thin cylindrical samples for the IFMIF and FNG cases are shown in Figure 2 and Figure 3, respectively.

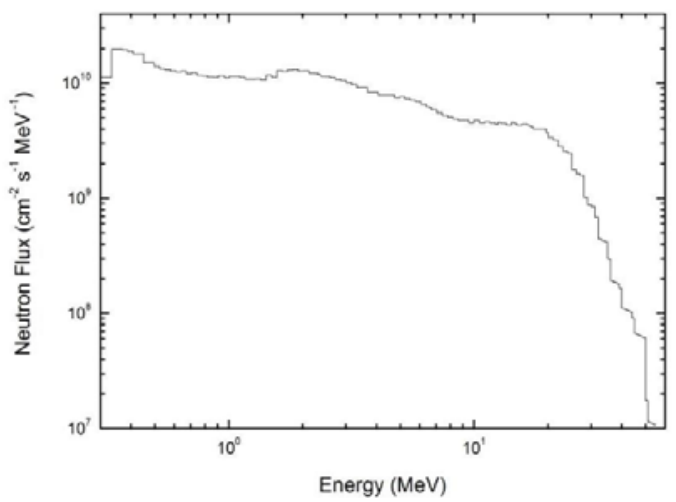

Figure 2. The IFMIF irradiating neutron spectrum [8].

In the IFMIF case, an energetic neutron spectrum (upper energy $\sim 55 \mathrm{MeV}$ ) is present, whereas the typical fusion neutron spectrum, peaked at $\sim 14 \mathrm{MeV}$, is present in the FNG case. The irradiation and cooling times, as well as sample material compositions of the samples, are here summarized in Table 4. The total number of irradiating scenarios considered for the Experimental case studies was equal to:

$$
\#_{F N G_{-} \text {Cases }}+\#_{I F M I F_{-} \text {Cases }}=13+4=17
$$




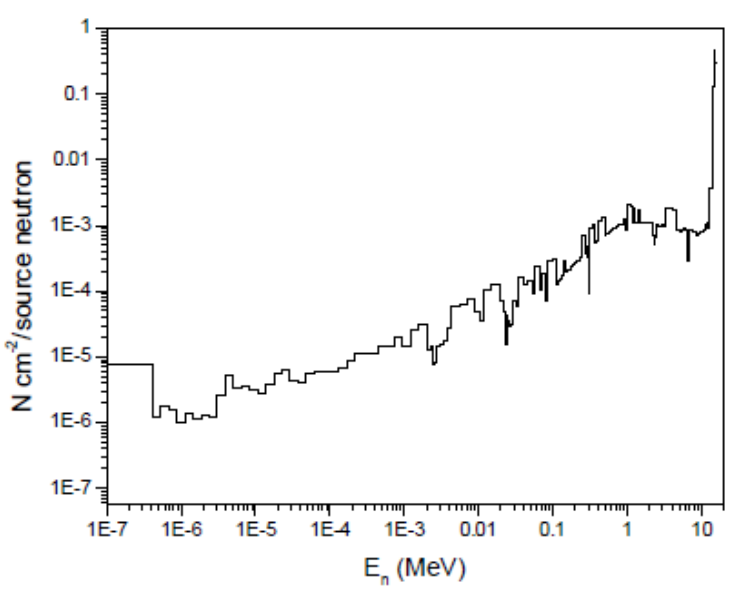

Figure 3. The FNG irradiating neutron spectrum [9].

Table 4. List of the irradiation parameter values [8] [9] considered in the present work for the "experimental case studies". Each line in the table represents an irradiation scenario.

\begin{tabular}{|c|c|c|c|c|}
\hline Case & $\begin{array}{l}\text { Sample } \\
\text { Materi } \\
\text { al }\end{array}$ & $\begin{array}{c}\text { Flux } \\
\text { intensity } \\
{\left[\mathbf{n} / \mathbf{c m}^{2} / \mathbf{s}\right]}\end{array}$ & $\begin{array}{c}\text { Irradi } \\
\text { ation } \\
\text { time } \\
{[s]}\end{array}$ & $\begin{array}{l}\text { Cooling time } \\
\text { instants [s] }\end{array}$ \\
\hline \multirow{4}{*}{ IFMIF } & SS316 & $4.10 \mathrm{e} 11$ & 7525 & $\begin{array}{c}5965,18848, \\
93333,178860, \\
432539, \\
2520240, \\
12962640\end{array}$ \\
\hline & $\mathrm{F} 82 \mathrm{H}$ & $4.14 \mathrm{e} 11$ & 7525 & $\begin{array}{c}4173,18011, \\
92043,158665, \\
424416, \\
2922060, \\
13036200\end{array}$ \\
\hline & V-alloy & $4.22 \mathrm{e} 11$ & 7525 & $\begin{array}{c}5477,17189, \\
90710,417962, \\
2254080, \\
13341780\end{array}$ \\
\hline & V-pure & $4.27 \mathrm{e} 11$ & 7525 & $\begin{array}{c}4983,16396, \\
90001,412474, \\
3100500, \\
13146900\end{array}$ \\
\hline \multirow{13}{*}{ FNG } & Mo & $3.13 \mathrm{e} 8$ & 330 & $\begin{array}{c}148,320,625 \\
926\end{array}$ \\
\hline & $\mathrm{Cu}$ & $2.46 \mathrm{e} 8$ & 161 & $\begin{array}{c}172,348,880, \\
1443\end{array}$ \\
\hline & $\mathrm{Hf}$ & $4.71 \mathrm{e} 8$ & 300 & $\begin{array}{c}136,318,638 \\
963\end{array}$ \\
\hline & $\mathrm{Mg}$ & $4.64 \mathrm{e} 8$ & 300 & $\begin{array}{c}136,316,616 \\
958\end{array}$ \\
\hline & $\mathrm{Ni}$ & $5.72 \mathrm{e} 8$ & 600 & $\begin{array}{c}139,318,617 \\
918\end{array}$ \\
\hline & $\mathrm{Cd}$ & $4.23 \mathrm{e} 8$ & 300 & $\begin{array}{c}136,317,618, \\
917 \\
\end{array}$ \\
\hline & Tin & $3.70 \mathrm{e} 8$ & 300 & $\begin{array}{c}137,316,616, \\
917\end{array}$ \\
\hline & $\operatorname{Re}$ & $5.56 \mathrm{e} 8$ & 1500 & $\begin{array}{c}136,318,619 \\
919,1141\end{array}$ \\
\hline & $\mathrm{Ti}$ & $4.97 \mathrm{e} 8$ & 600 & $\begin{array}{c}137,317,617, \\
918\end{array}$ \\
\hline & W & $5.63 \mathrm{e} 8$ & 1500 & $\begin{array}{c}139,320,619, \\
923,1085\end{array}$ \\
\hline & $\mathrm{Ag}$ & $2.42 \mathrm{e} 8$ & 300 & $\begin{array}{c}138,319,621, \\
923\end{array}$ \\
\hline & $\mathrm{Al}$ & $4.73 \mathrm{e} 8$ & 600 & $\begin{array}{c}138,323,621 \\
922\end{array}$ \\
\hline & $\mathrm{Al}$ & $3.24 \mathrm{e} 8$ & 901 & 4547,6324 \\
\hline
\end{tabular}

\subsubsection{The calculational methodology}

Since all the irradiation scenarios in the Experimental case studies had very thin samples (sample thickness $<$ $25 \mu \mathrm{m}$ in FNG cases [9], similar conditions are assumed for the IFMIF cases), in the present work it was assumed that the irradiating neutron fluxes shown in Figure 2 and Figure 3 were not significantly modified or attenuated in the samples. Hence, the samples were assumed to have an homogeneous and isotropic distribution of these neutron fluxes inside their volumes.

By consequence, in the Monte Carlo approach with FLUKA and PHITS codes the irradiating source was defined differently with respect to the "Calculational case studies", since here the neutron energy spectra were defined as an homogeneous and isotropic volume source term. Again, the calculation of the residual specific activity at the requested cooling time instants were performed automatically during the Monte Carlo run via the RESNUCLEI card or via the dedicated post-Monte Carlo processing code "dchain-sp", respectively.

In the analytical approach, the two-step method followed in the "Calculational case studies" was no more necessary since the irradiating neutron fluxes could be just defined as the input irradiating flux without any modification, thus performing directly the single step method of the deterministic calculation.

It is here underlined that, apart from the experimental results, in [8] and [9] the results of corresponding calculations with ANITA (both for FNG and IFMIF cases) and FISPACT (for FNG cases) were already available; hence, these calculations were not repeated in this work, and results are here reported as taken from these references.

The information on the code versions and nuclear dataset used in the calculations is reported in Table 5.

Table 5. Code name, version and nuclear dataset (transmutation cross section) used in the calculations of the "Experimental case studies".

\begin{tabular}{|c|c|c|c|}
\hline Code name & Version & $\begin{array}{c}\text { Nuclear } \\
\text { dataset }\end{array}$ & $\begin{array}{c}\text { Irradiation } \\
\text { scenarios }\end{array}$ \\
\hline FLUKA & $2011.2 \mathrm{c}$ & Proprietary & $\begin{array}{c}\text { All the } \\
\text { scenarios }\end{array}$ \\
\hline PHITS & 2.82 & JENDL 4.0 & $\begin{array}{c}\text { All the } \\
\text { scenarios } \\
\text { FISPACT }\end{array}$ \\
\hline ANITA* $^{\ddagger}$ & IEAF & IEAF2001 & IFMIF \\
\cline { 2 - 4 } & $4 \mathrm{M}$ & EAF2010 & FNG \\
\hline
\end{tabular}

* Proprietary versions of the ANITA code developed by ENEA Italy. The corresponding calculations were not performed for the present work and the results were taken from [8] (IFMIF case) and [9] (FNG case).

₹ The calculations with this code were performed for the present work only in the IFMIF case. The results of the FNG case were taken from [9]. 


\subsection{Uncertainty Estimation}

A detailed analysis of the uncertainties was considered out of the scope of the present work. When available from the codes, the errors on the total specific activities were evaluated and reported also in the graphs as error bars. Depending on the code, the error associated to the total specific activity value is either due to statistics (for Monte Carlo codes) or estimated by evaluated data libraries (for analytical codes). As stated before, all the Monte Carlo calculations were performed setting an appropriate number of starting particles so that the output results (total activity and track-length estimator values) had a relative error well below $1 \%$ in all the cases. The eventual contribution of secondary particles (i.e., primarily, neutron particles in case of proton irradiating particles and vice versa) was considered during the definition of the methodology and the execution of the calculations; indeed, in some of the considered codes the evaluation of this contribution is embedded or estimated in the calculation by dedicated models. Anyway, some sensitivities were preliminary performed in several case studies considered in the present work in order to discern the percent contribution to the total specific activities of the secondary particles: in all the considered cases, it was found that this contribution is no more than few percent of the one of the primary particles. Hence, for simplicity, the contribution of the secondary particles was neglectedby consequence, a systematic underestimation error ranging from about zero up to few percent of the total specific activity can be roughly considered in the final results reported in the present paper.

\section{Results and Conclusions}

In the present Section the results of the calculations and the comparison among them are reported both for the calculation and for the experimental case studies.

\subsection{The Calculational Case Studies}

The behaviour of the total specific activity of the SS316 and Portland Concrete samples for each irradiation scenarios are reported hereafter.

Looking at the results from Figure 4 through Figure 27, in general it can be concluded that a good agreement among the results obtained with the different codes is observed. On average, differences of the order of factor of a few are present. Very few cases, in particular for high cooling time instants, do present big differences (factor 10 and more) among the codes.

In particular, the results of SS316 are in better agreement among the codes than the Portland concrete ones. It is suggested that this is due to some difference on the dominating activated isotopes in Portland among the nuclear dataset used in the calculations. Moreover, the results in thin samples are in better agreement among the codes than the thick ones. It is suggested that it is due to the fact that in the thick cases the averaged irradiating energy spectra are no more monochromatic in energy as the source is, and a wider range of energy values is spanned: the results are then again potentially more sensitive to differences on the cross section shape versus energy among the different nuclear dataset.

\subsubsection{Thermal (2.5e-8 MeV) neutrons}

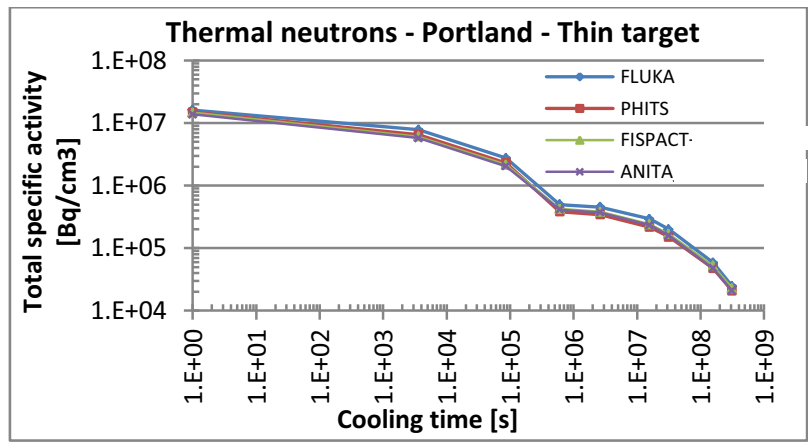

Figure 4.

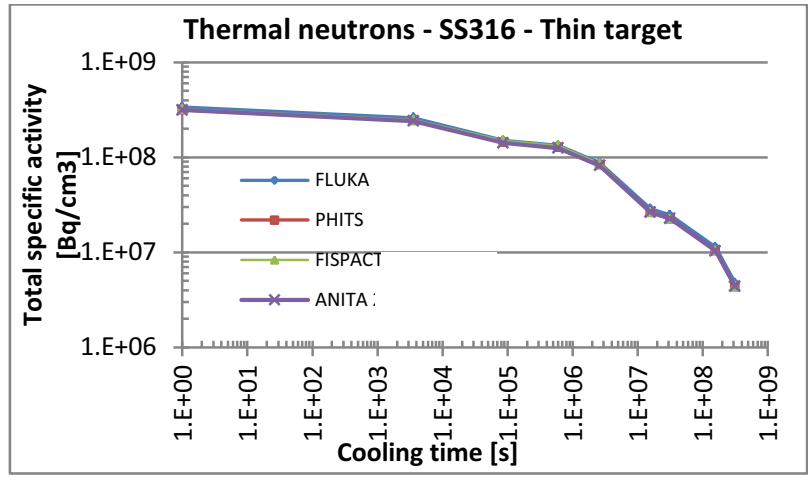

Figure 5.

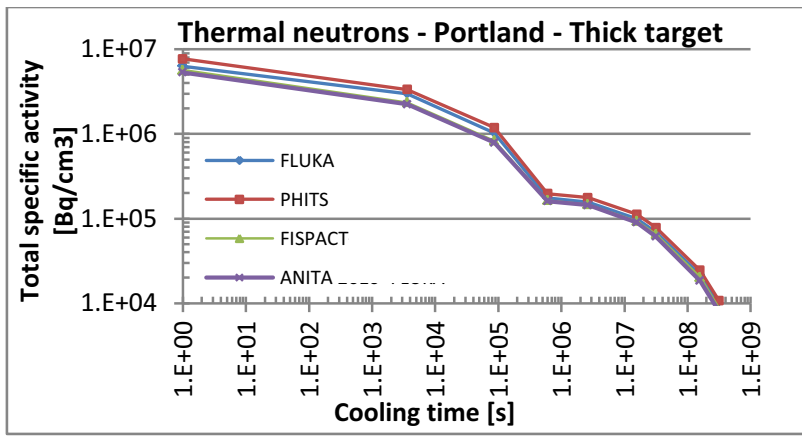

Figure 6.

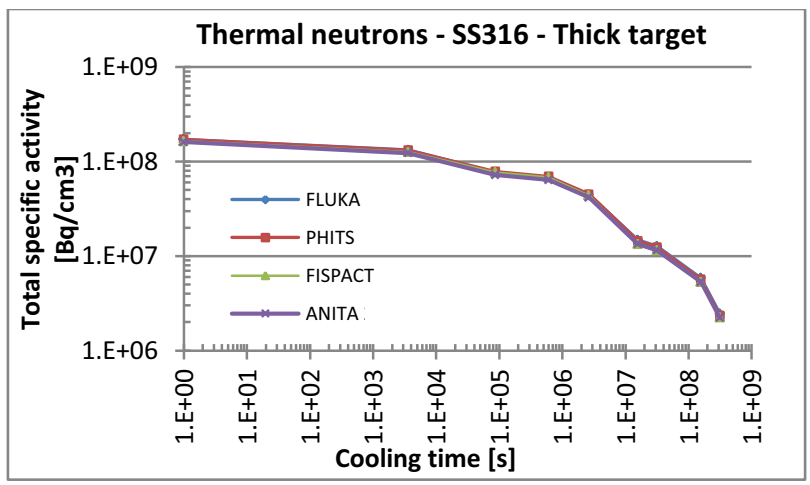

Figure 7. 


\subsection{2 $10 \mathrm{MeV}$ protons}

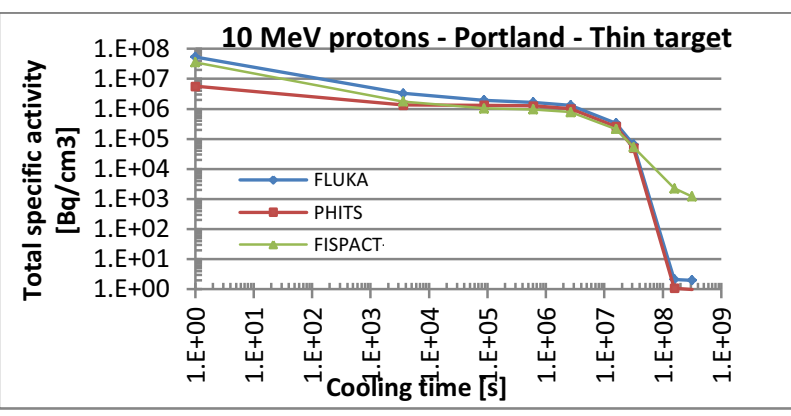

Figure 8.

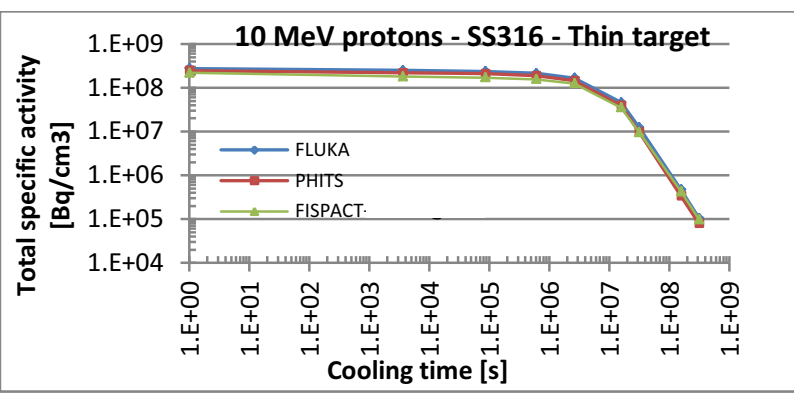

Figure 9.

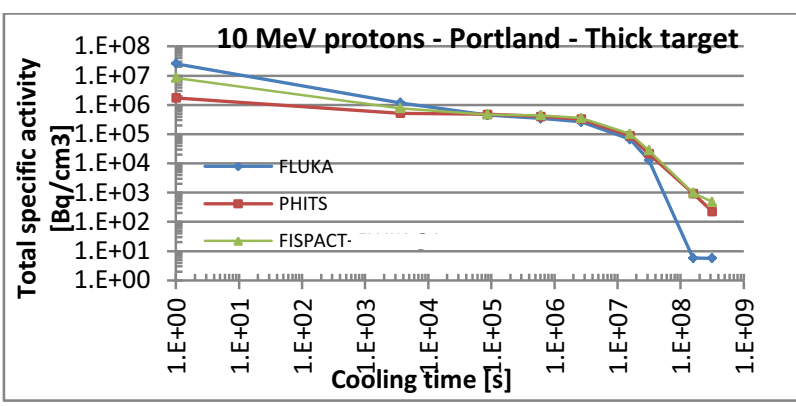

Figure 10.

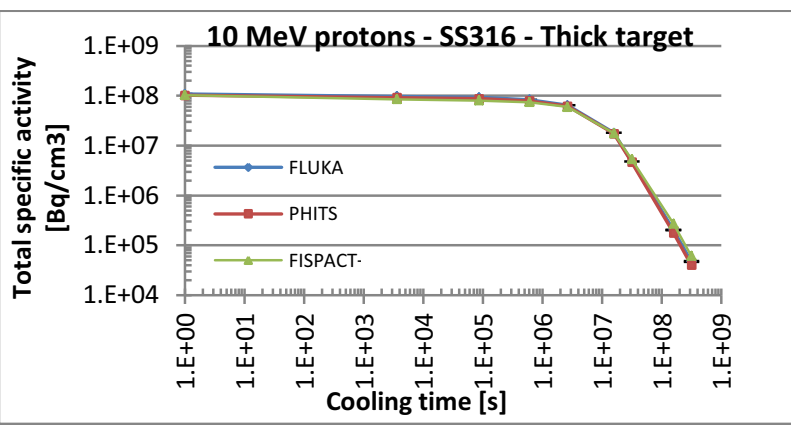

Figure 11.

\subsection{3 $50 \mathrm{MeV}$ neutrons}

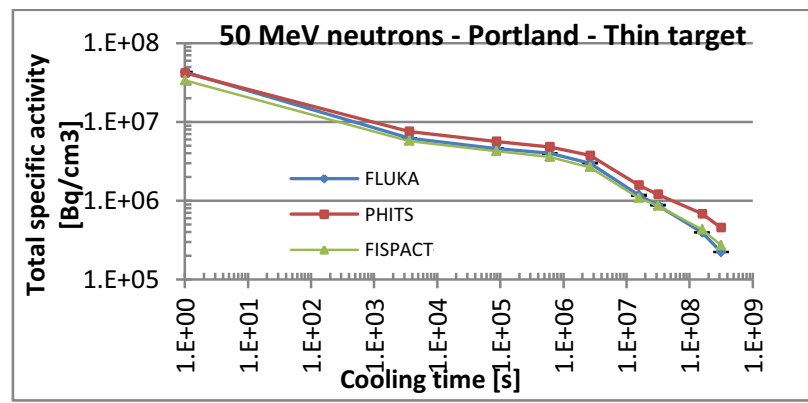

Figure 12.

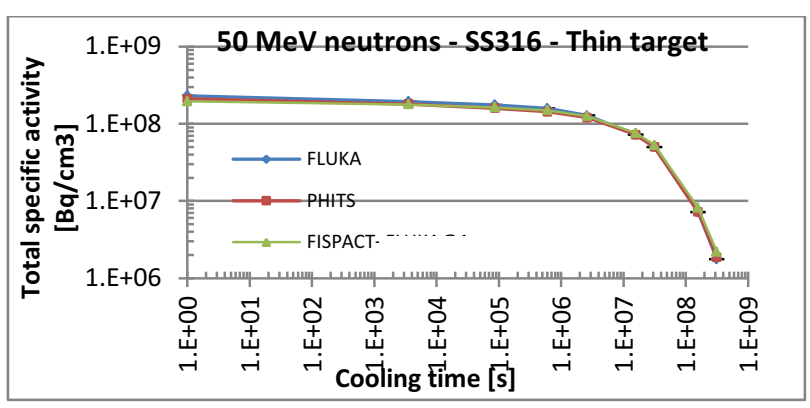

Figure 13.

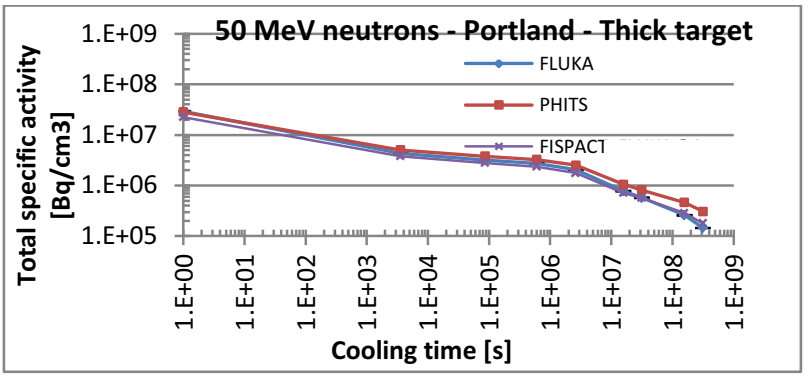

Figure 14.

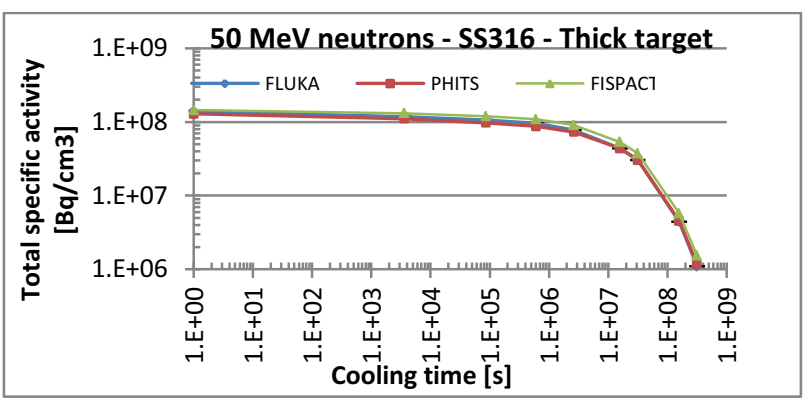

Figure 15.

\subsection{4 $50 \mathrm{MeV}$ protons}

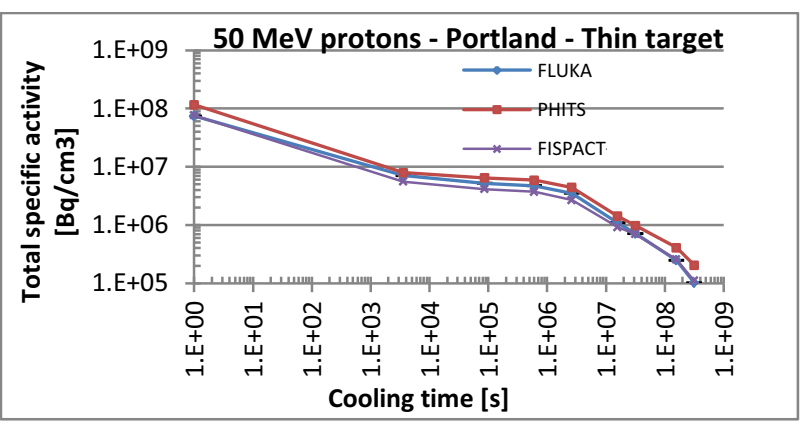

Figure 16.

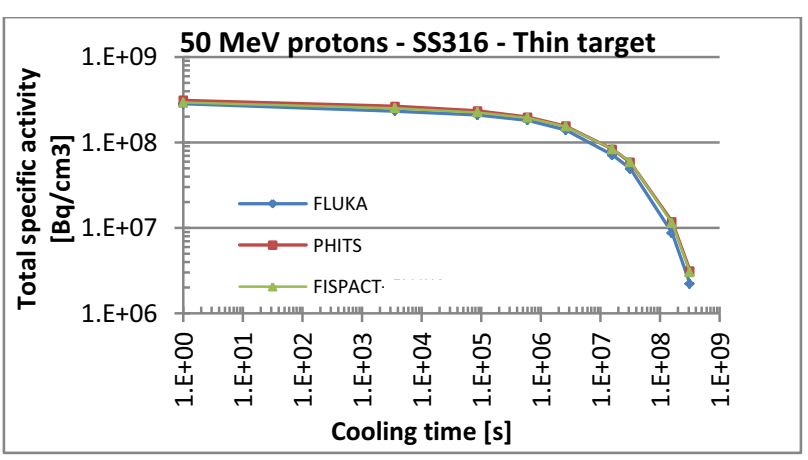

Figure 17. 


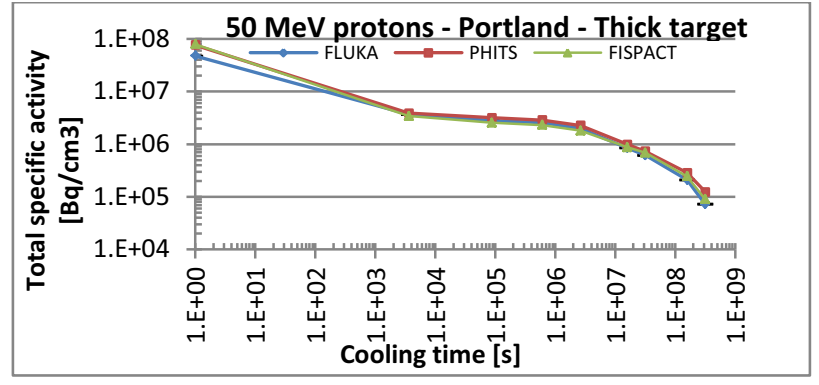

Figure 18.

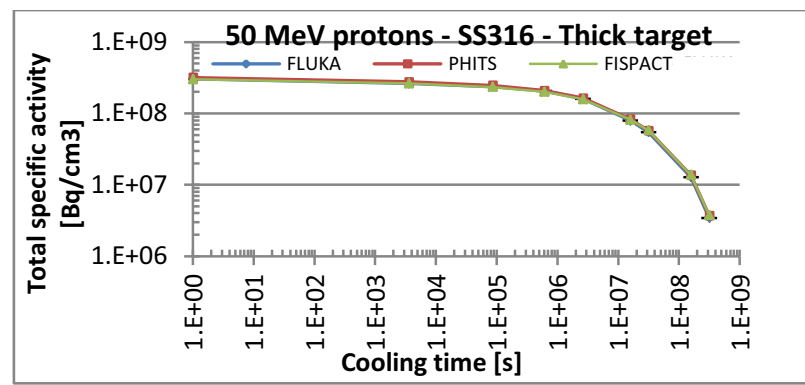

Figure 19.

\subsection{5 $200 \mathrm{MeV}$ neutrons}

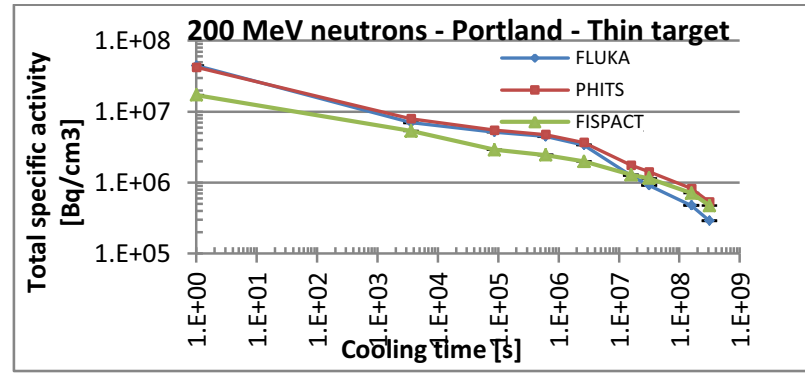

Figure 20.

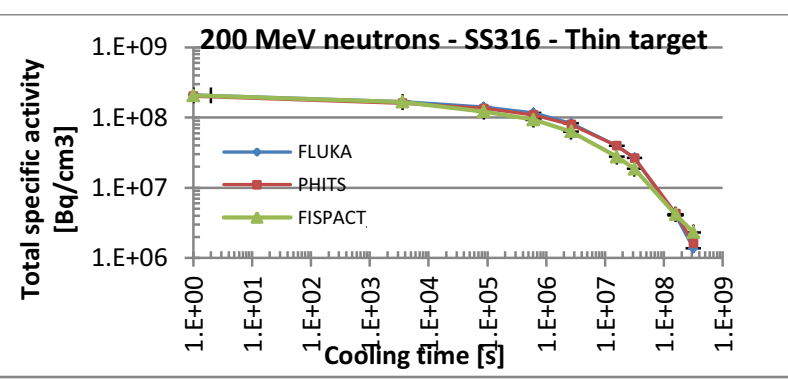

Figure 21.

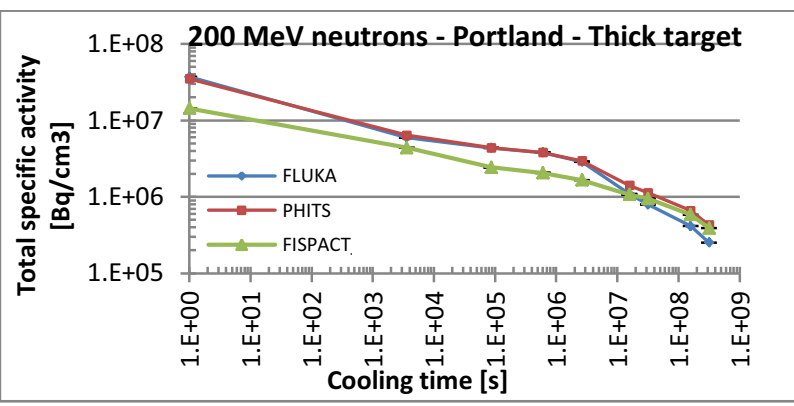

Figure 22.

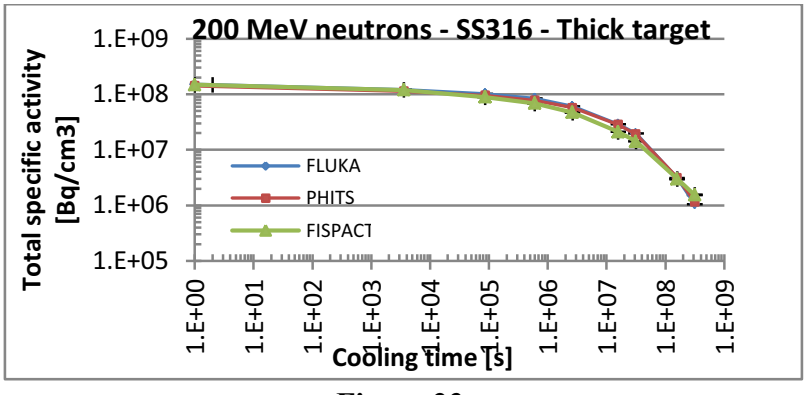

Figure 23.

\subsection{6 $600 \mathrm{MeV}$ protons}

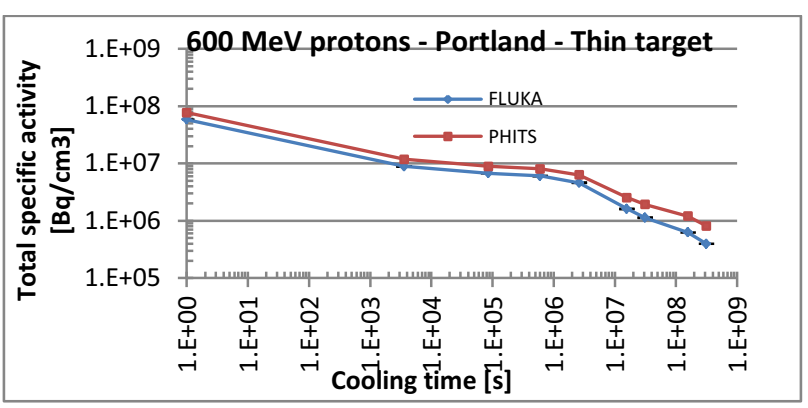

Figure 24.

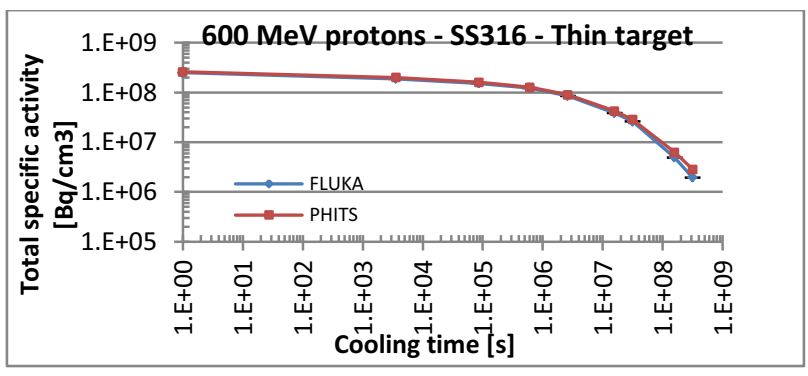

Figure 25.

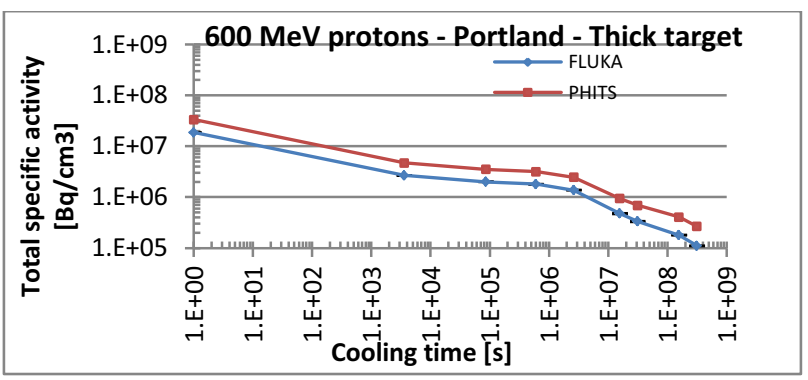

Figure 26.

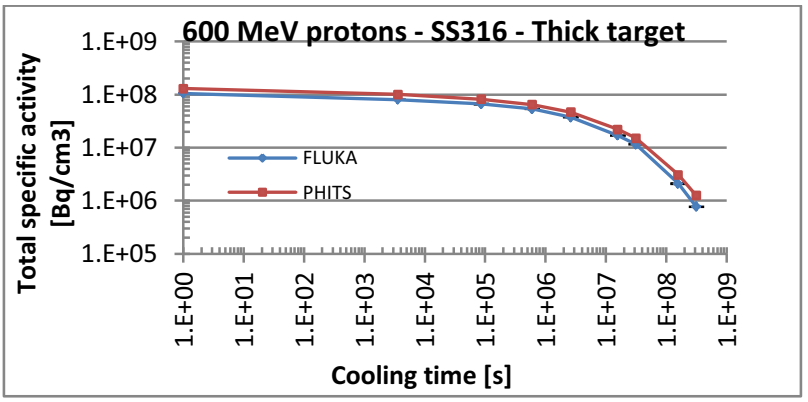

Figure 27. 


\subsection{The Experimental Case Studies}

The behaviour of the total specific activity of some pure elements and of SS316 thin samples for each irradiation scenarios are reported hereafter as obtained from the calculations. The comparison with experimental data and the corresponding $\mathrm{C} / \mathrm{E}$ (calculation over experiment) values are also reported. Their error values $(1 \sigma)$ are not reported in the graphs for convenience, and reported in Table 6 and Table 7.

Looking at the results from Figure 28 through Figure 53, it can be concluded that in almost all the FNG cases the results of the different codes are in good agreement (few tens percent difference among them) and in agreement within a factor of 2 at maximum with respect to the experiment values. Only in the Hafnium case, probably because of issues on the nuclear dataset, very big differences are present between the calculations and the experiment.

Finally, looking at the results from Figure 54 through Figure 61, also for the IFMIF cases a good agreement among the calculation results was observed, and an acceptable agreement within a factor 4 at maximum was found against the experimental values in all the cases except the Vanadium ones, where the disagreement went up to more than a factor 10 for long cooling time instants ("Fluka 3"), again probably because of nuclear data issue. Also the calculation results obtained with FLUKA in the Vanadium cases at long cooling time instants were found not to be in good agreement with the other codes: it was found that it was related to an overestimation of the ${ }^{65} \mathrm{Zn}$ isotope contribution: by eliminating it, as shown in Figure 58 and Figure 60 ("Fluka_3 - Zn65" label), the FLUKA results are closer both the experimental and the calculated results of the other codes ${ }^{\mathrm{b}}$.

\subsubsection{FNG - Molybdenum sample}

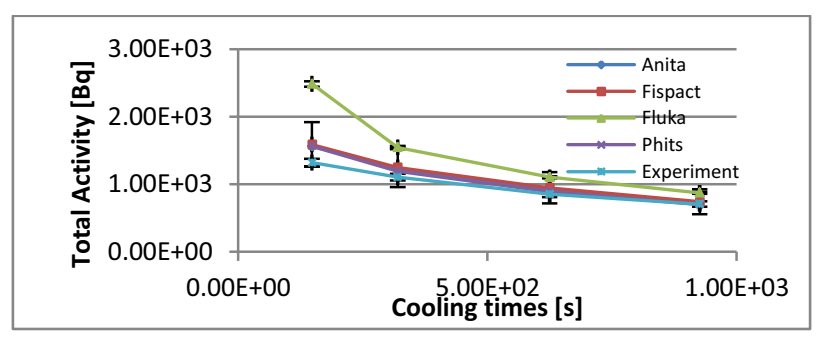

Figure 28.

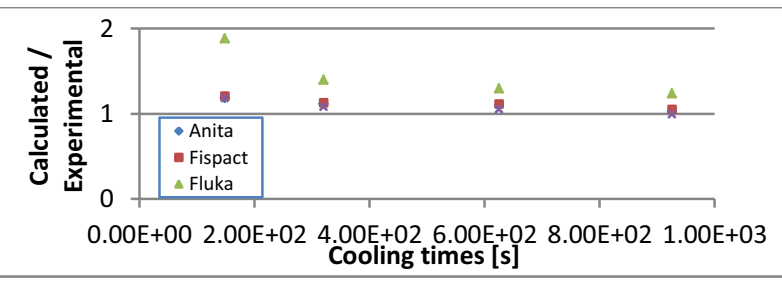

Figure 29.

\footnotetext{
$\mathrm{b}$ This issue was discussed with the FLUKA Developers. It was found that there was a minor bug since the ${ }^{65} \mathrm{Zn}$ libraries were wrongly linked by the software. A new FLUKA version was then released in October 2016 (i.e. FLUKA 2011.2c.5). The Vanadium cases were then computed again, showing that this issue was solved (see Figure 58 and Figure 60, label « Fluka_5 »).
}

\subsubsection{FNG - Copper sample}

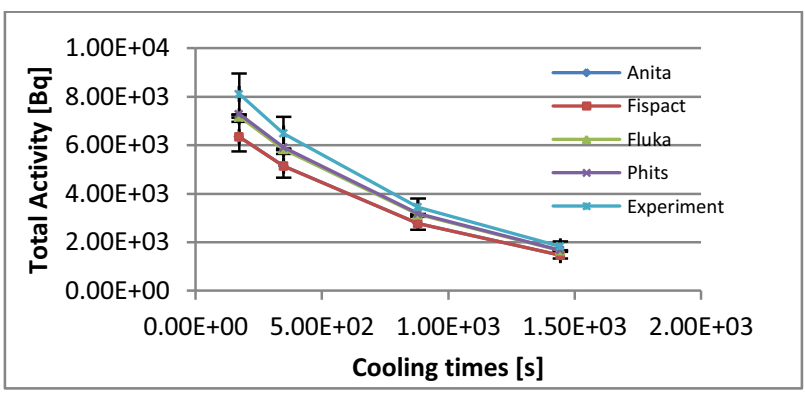

Figure 30.

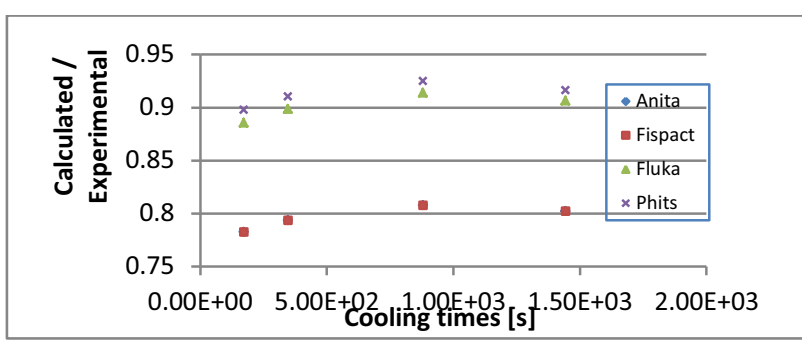

Figure 31 .

\subsubsection{FNG - Hafnium sample}

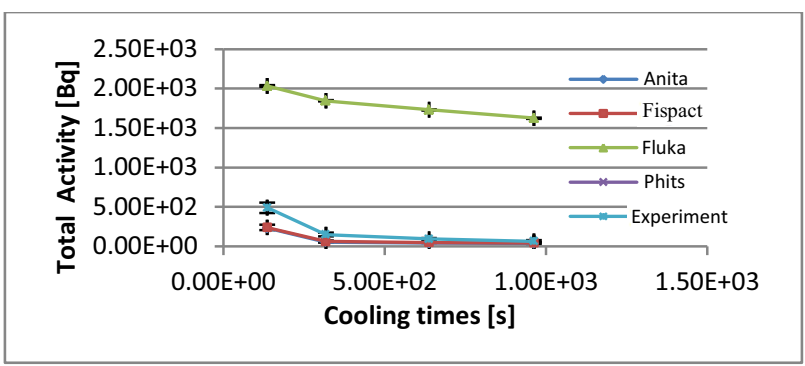

Figure 32.

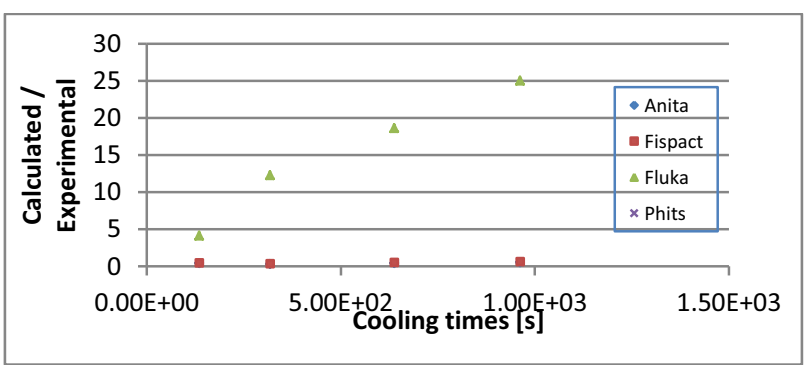

Figure 33.

\subsubsection{FNG - Magnesium sample}

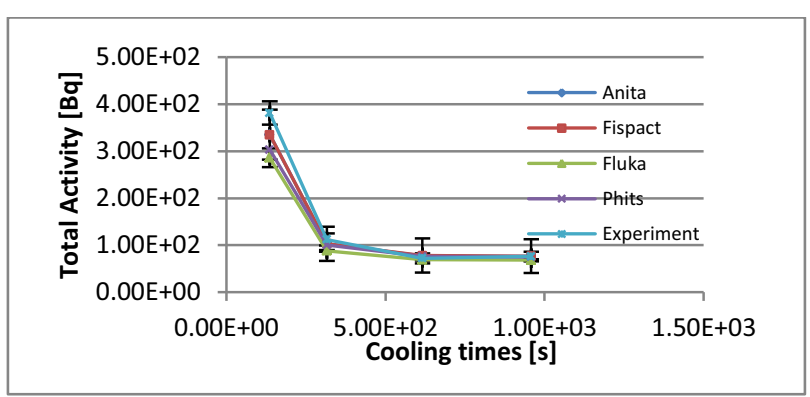

Figure 34 . 


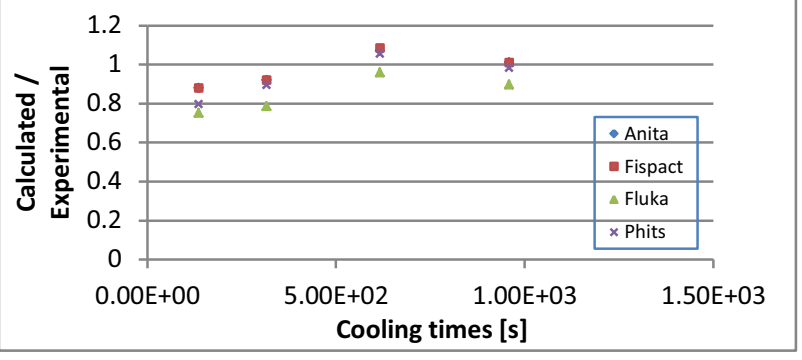

Figure 35.

\subsubsection{FNG - Nichel sample}

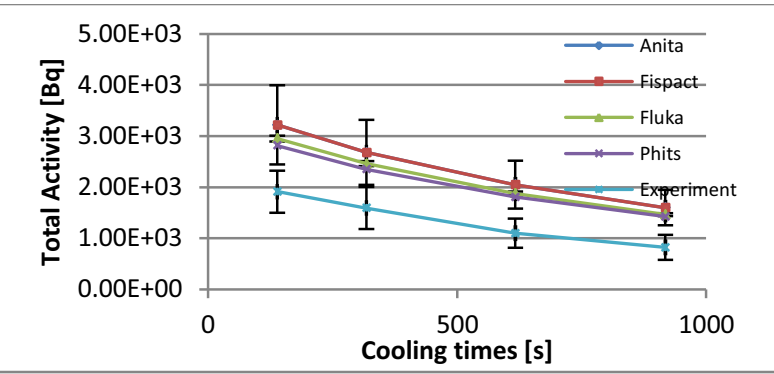

Figure 36.

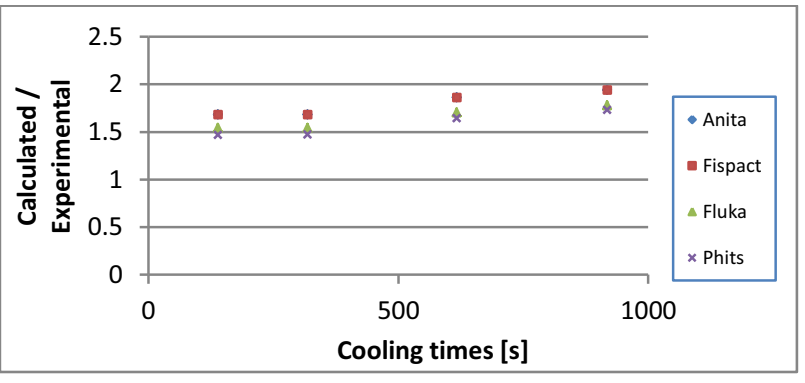

Figure 37.

\subsubsection{FNG - Cadmium sample}

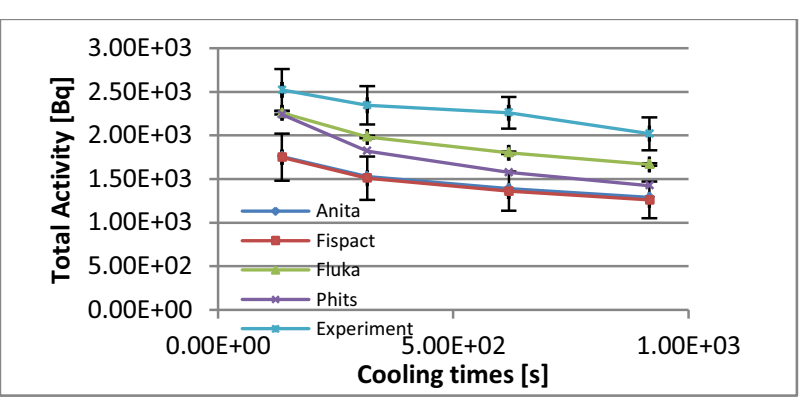

Figure 38.

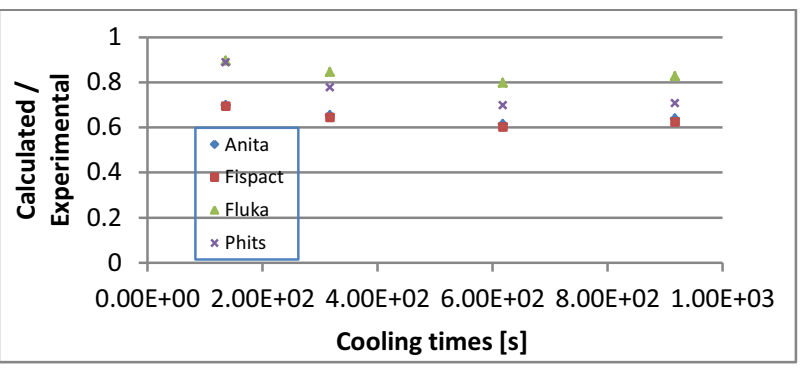

Figure 39.

\subsubsection{FNG - Tin sample}

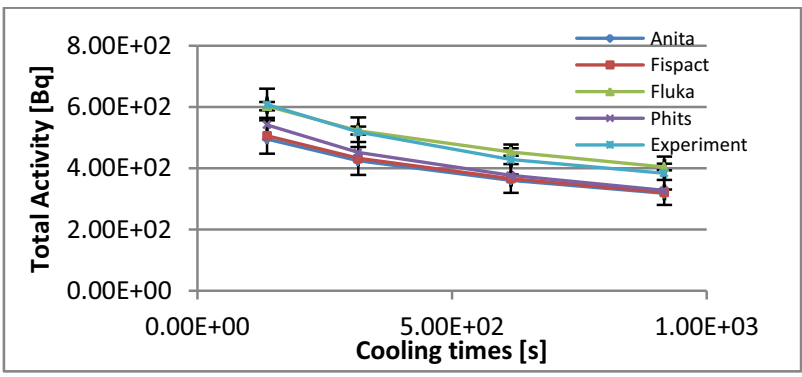

Figure 40.

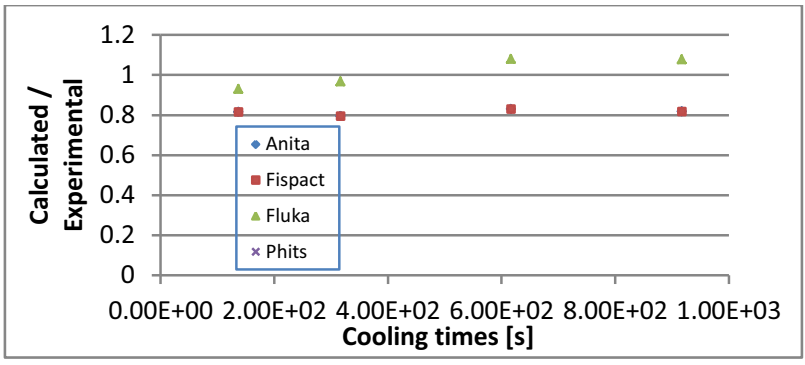

Figure 41.

\subsubsection{FNG - Rhenium sample}

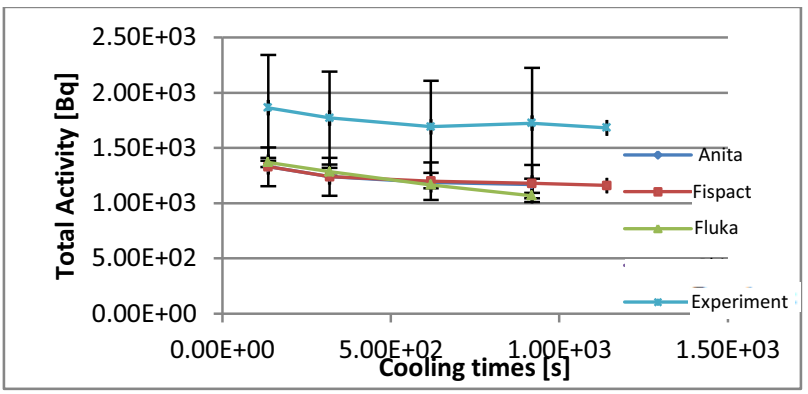

Figure 42.

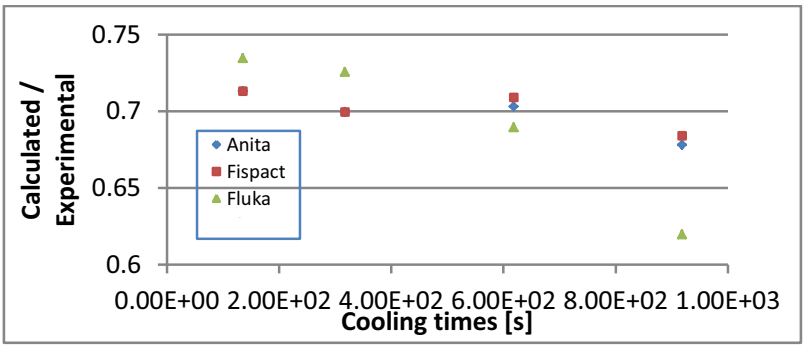

Figure 43.

\subsubsection{FNG - Titanium sample}

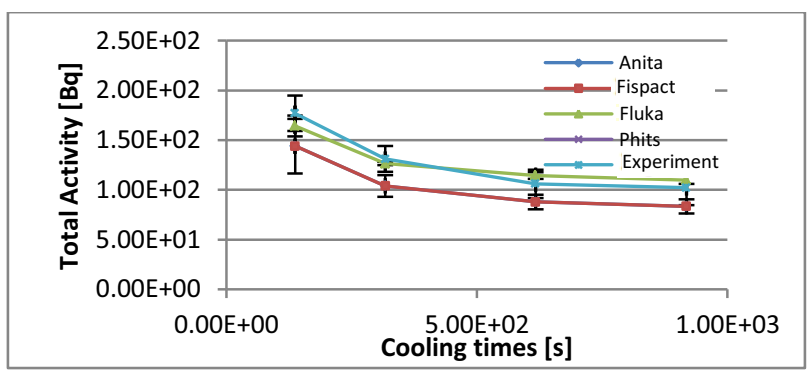

Figure 44. 


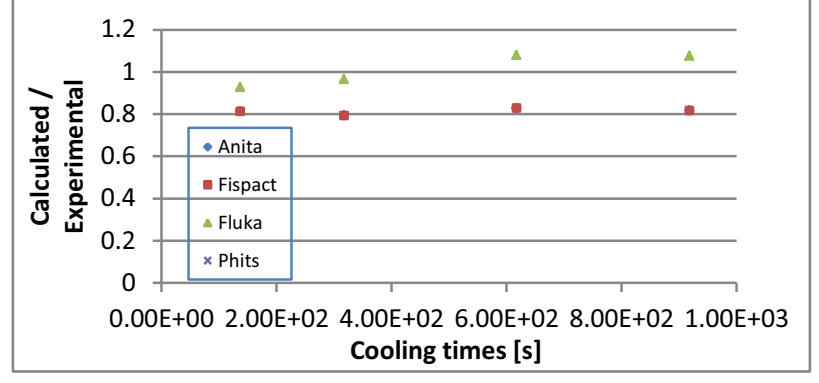

Figure 45.

\subsubsection{FNG - Tungsten sample}

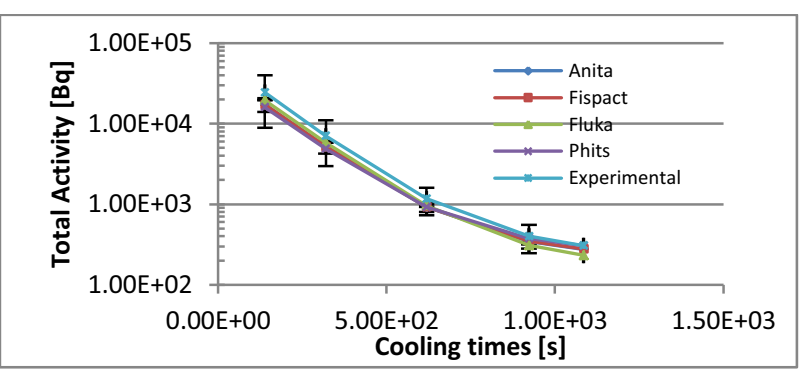

Figure 46.

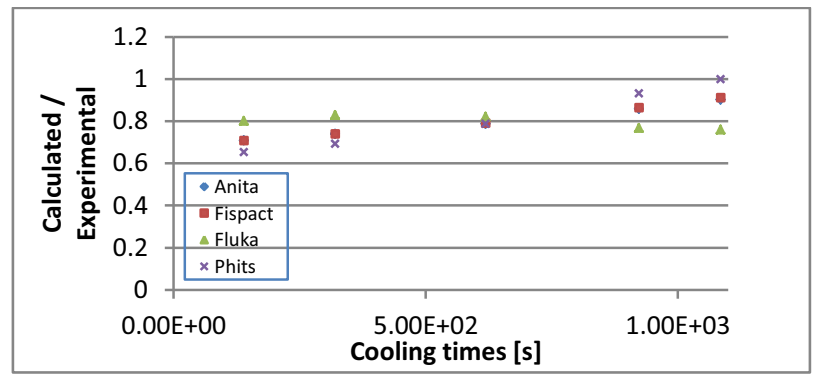

Figure 47.

\subsubsection{FNG - Silver sample}

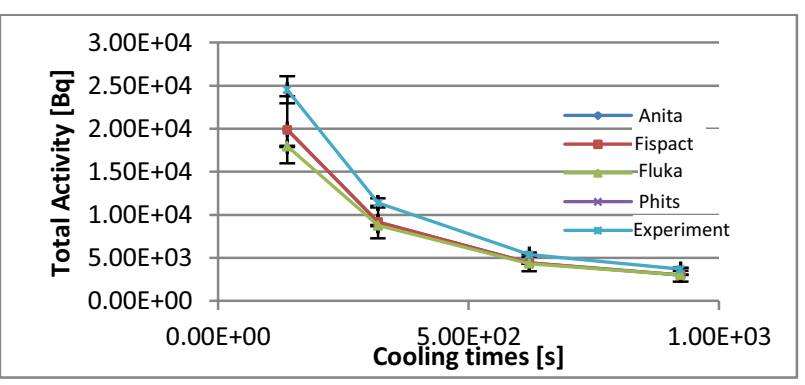

Figure 48.

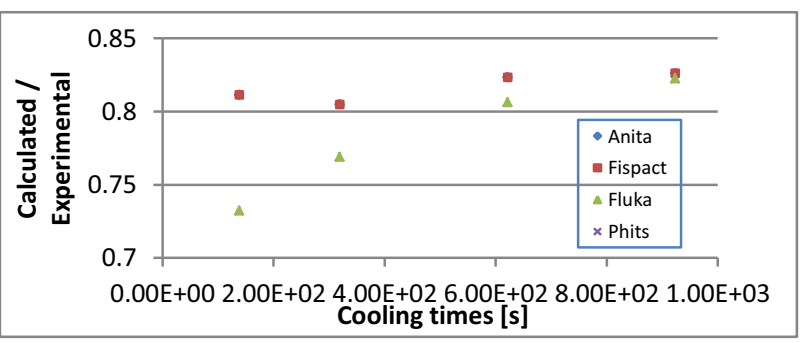

Figure 49.

\subsubsection{FNG - Aluminium sample number 1}

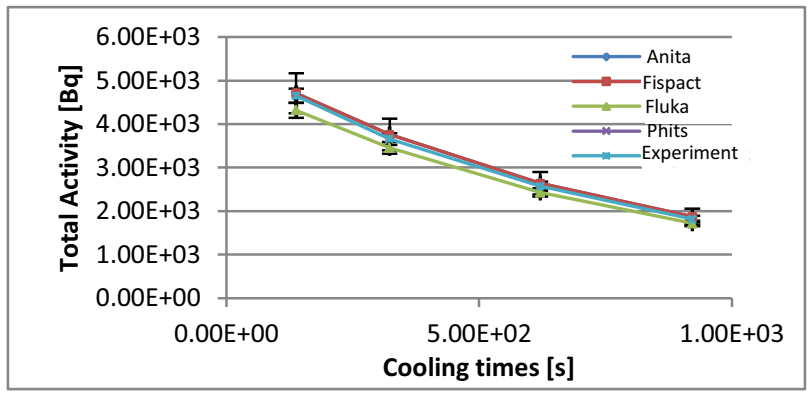

Figure 50.

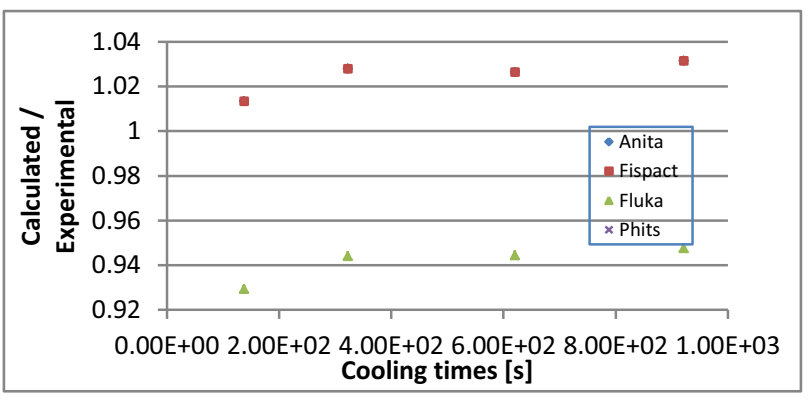

Figure 51.

\subsubsection{FNG - Aluminium sample number 2}

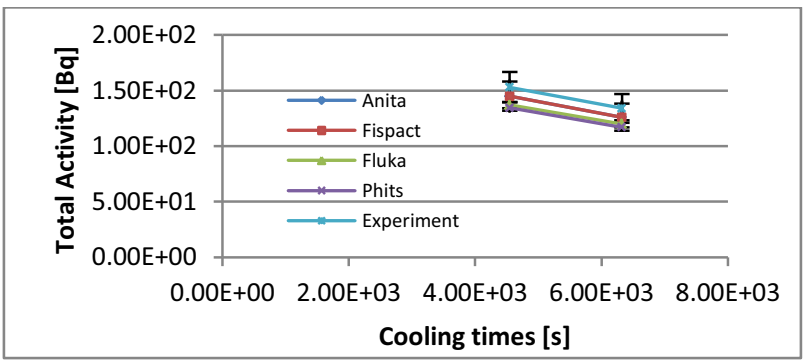

Figure 52.

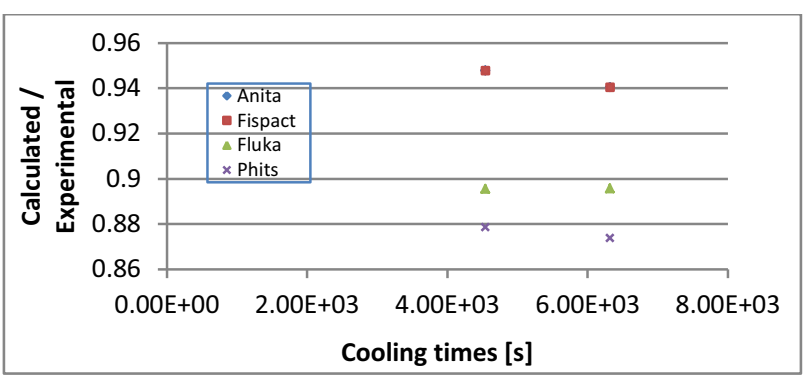

Figure 53. 


\subsubsection{IFMIF - SS316 sample}

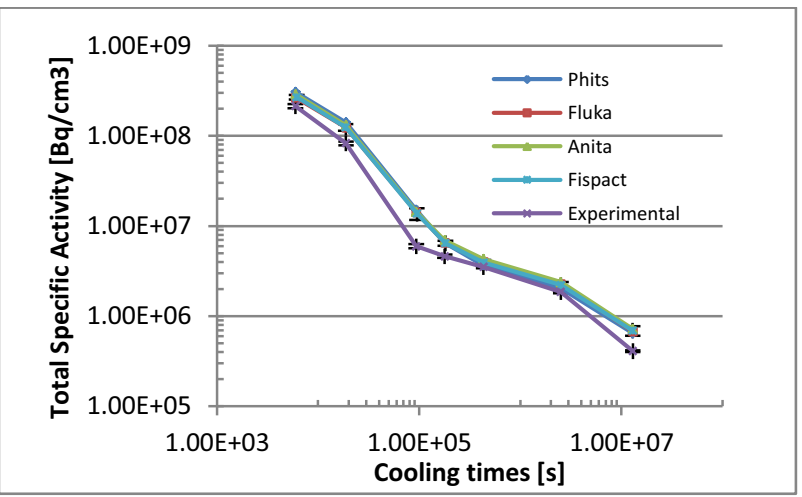

Figure 54.

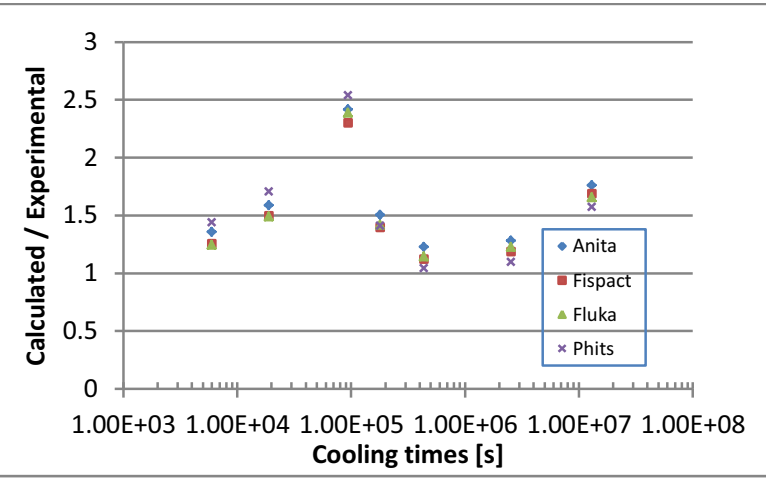

Figure 55.

\subsubsection{IFMIF - F82H sample}

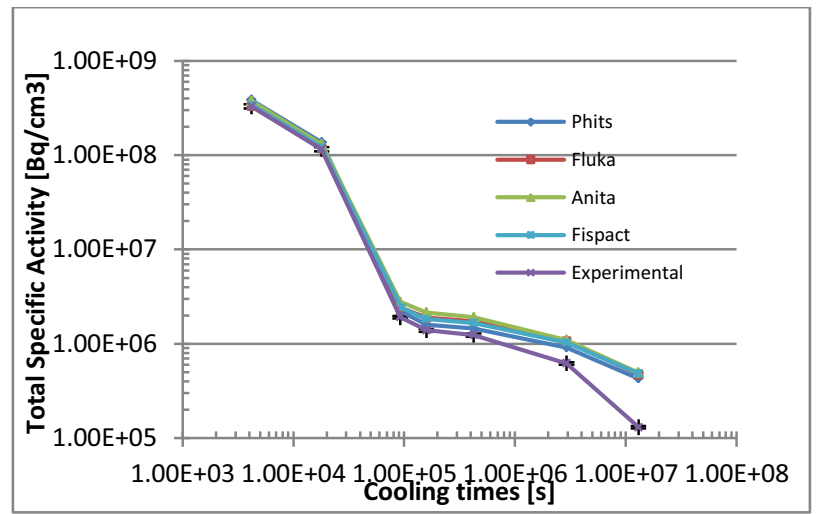

Figure 56.

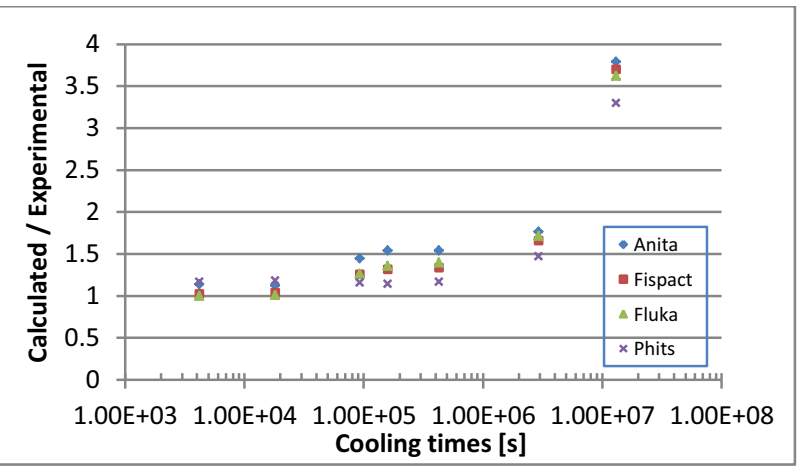

Figure 57.

\subsubsection{IFMIF - V-alloy sample}

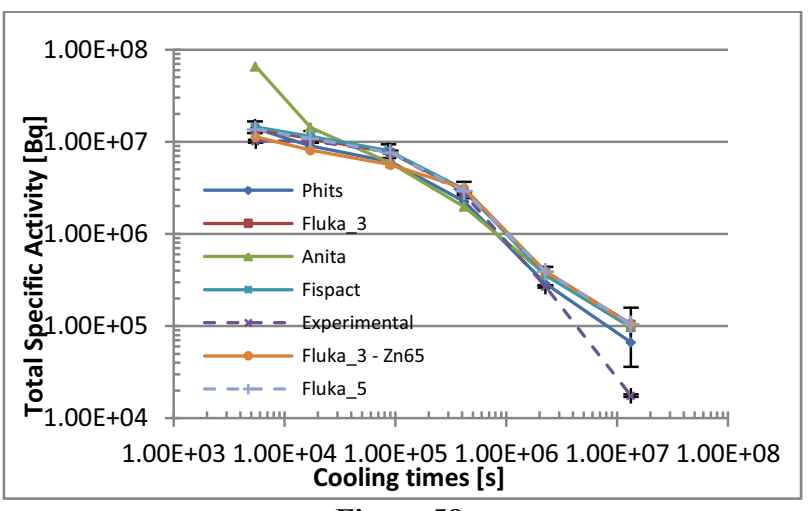

Figure 58.

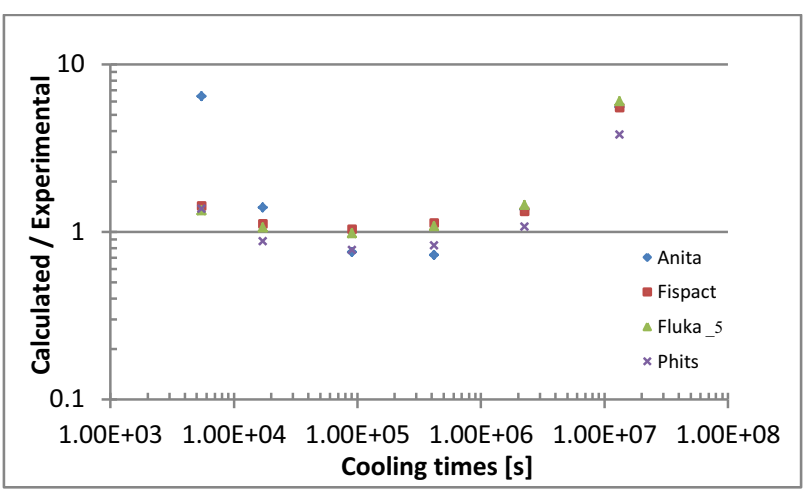

Figure 59.

\subsubsection{IFMIF - V-pure sample}

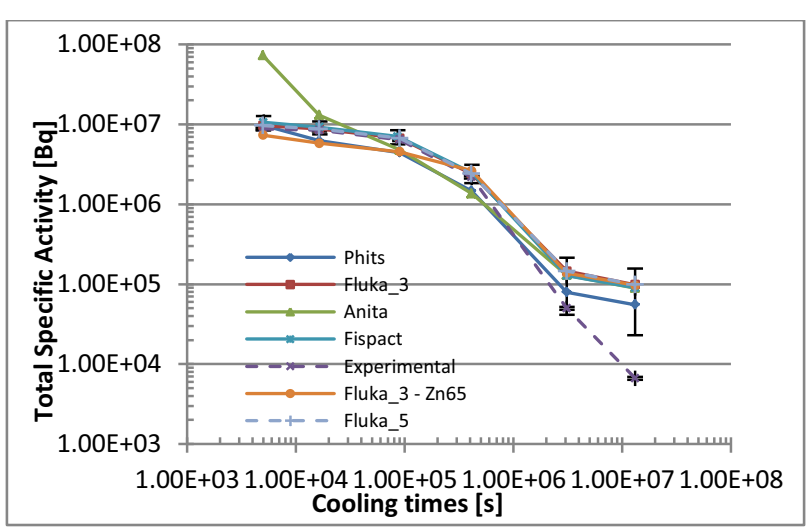

Figure 60.

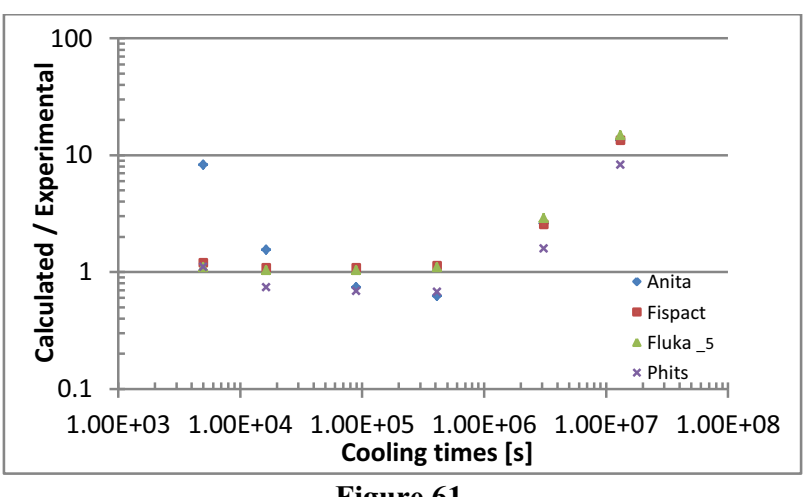

Figure 61. 


\subsection{Additional Notes}

Apart from the total specific activity values, in principle it could have been also possible to compare the detailed list of nuclide inventories obtained by the different codes; anyway, for simplicity this analysis was not systematically performed in the present work, and the corresponding results are not reported. It is just underlined here that this analysis was performed in some cases, looking at the list of the nuclides in decreasing order of their contribution to the total specific activity. In general it was noted that, from the qualitative point of view, the dominating 4 or 5 nuclides in the isotopic inventories are typically the same for all the codes-just some position exchange in this list was observed among the codes - whereas, going on through the list, where the contribution of the nuclides goes well below $1 \%$ of the total specific activity, the scenarios are completely different among the codes. It is suggested that this is due primarily to the different nuclear dataset used by the codes.

Table 6. Summary of the C/E values for the IFMIF cases.

\begin{tabular}{|c|c|c|c|c|c|c|c|c|c|}
\hline \multirow[b]{2}{*}{ Sample } & \multirow[b]{2}{*}{ Cooling time $[\mathrm{s}]$} & \multicolumn{2}{|c|}{ Anita } & \multicolumn{2}{|c|}{ Fispact } & \multicolumn{2}{|c|}{ Fluka } & \multicolumn{2}{|c|}{ Phits } \\
\hline & & $\mathbf{C} / \mathbf{E}$ & $\sigma_{C / E}$ & $\mathrm{C} / \mathrm{E}$ & $\sigma_{C I E}$ & $\mathrm{C} / \mathbf{E}$ & $\sigma_{C / E}$ & $\mathrm{C} / \mathrm{E}$ & $\sigma_{C / E}$ \\
\hline \multirow{7}{*}{ SS316 } & 5965 & 1.36 & 0.07 & 1.26 & 0.09 & 1.24 & 0.06 & 1.44 & 0.07 \\
\hline & 18848 & 1.59 & 0.08 & 1.50 & 0.14 & 1.49 & 0.07 & 1.71 & 0.08 \\
\hline & 93333 & 2.42 & 0.13 & 2.30 & 0.36 & 2.39 & 0.13 & 2.54 & 0.13 \\
\hline & 178860 & 1.50 & 0.06 & 1.40 & 0.11 & 1.42 & 0.06 & 1.41 & 0.06 \\
\hline & 432539 & 1.23 & 0.04 & 1.12 & 0.09 & 1.15 & 0.04 & 1.04 & 0.03 \\
\hline & 2520240 & 1.28 & 0.04 & 1.19 & 0.11 & 1.23 & 0.04 & 1.10 & 0.04 \\
\hline & 12962640 & 1.76 & 0.05 & 1.69 & 0.21 & 1.65 & 0.04 & 1.57 & 0.04 \\
\hline \multirow{7}{*}{$\mathrm{F} 82 \mathrm{H}$} & 4173 & 1.14 & 0.06 & 1.02 & 0.05 & 1.00 & 0.05 & 1.17 & 0.06 \\
\hline & 18011 & 1.12 & 0.06 & 1.04 & 0.06 & 1.01 & 0.05 & 1.18 & 0.06 \\
\hline & 92043 & 1.45 & 0.05 & 1.26 & 0.15 & 1.26 & 0.04 & 1.16 & 0.04 \\
\hline & 158665 & 1.54 & 0.06 & 1.32 & 0.19 & 1.36 & 0.05 & 1.15 & 0.05 \\
\hline & 424416 & 1.54 & 0.06 & 1.34 & 0.18 & 1.40 & 0.06 & 1.17 & 0.05 \\
\hline & 2922060 & 1.77 & 0.06 & 1.66 & 0.22 & 1.72 & 0.06 & 1.47 & 0.05 \\
\hline & 13036200 & 3.79 & 0.12 & 3.70 & 0.75 & 3.62 & 0.12 & 3.30 & 0.11 \\
\hline \multirow{6}{*}{ V_Alloy } & 5477 & 6.45 & 0.25 & 1.43 & 0.21 & 1.34 & 0.05 & 1.38 & 0.05 \\
\hline & 17189 & 1.40 & 0.05 & 1.12 & 0.17 & 1.06 & 0.04 & 0.88 & 0.03 \\
\hline & 90710 & 0.76 & 0.03 & 1.04 & 0.18 & 0.98 & 0.03 & 0.78 & 0.03 \\
\hline & 417962 & 0.73 & 0.02 & 1.13 & 0.23 & 1.08 & 0.03 & 0.83 & 0.03 \\
\hline & 2254080 & 1.36 & 0.04 & 1.33 & 0.31 & 1.45 & 0.05 & 1.08 & 0.04 \\
\hline & 13341780 & 5.58 & 0.18 & 5.53 & 3.48 & 6.01 & 0.19 & 3.80 & 0.12 \\
\hline \multirow{6}{*}{$\mathrm{V}$ pure } & 4983 & 8.28 & 0.31 & 1.21 & 0.25 & 1.10 & 0.04 & 1.11 & 0.04 \\
\hline & 16396 & 1.55 & 0.06 & 1.10 & 0.21 & 1.04 & 0.04 & 0.74 & 0.03 \\
\hline & 90001 & 0.74 & 0.03 & 1.09 & 0.22 & 1.04 & 0.04 & 0.69 & 0.03 \\
\hline & 412474 & 0.62 & 0.02 & 1.14 & 0.29 & 1.10 & 0.03 & 0.68 & 0.02 \\
\hline & 3100500 & 2.60 & 0.12 & 2.56 & 1.74 & 2.91 & 0.13 & 1.59 & 0.07 \\
\hline & 13146900 & 13.50 & 0.53 & 13.51 & 10.06 & 14.84 & 0.58 & 8.31 & 0.32 \\
\hline
\end{tabular}

Table 7. Summary of the C/E values for the FNG cases.

\begin{tabular}{|c|c|c|c|c|c|c|c|c|c|}
\hline \multirow[b]{2}{*}{ Sample } & \multirow[b]{2}{*}{ Cooling time $[\mathbf{s}]$} & \multicolumn{2}{|c|}{ Anita } & \multicolumn{2}{|c|}{ Fispact } & \multicolumn{2}{|c|}{ Fluka } & \multicolumn{2}{|c|}{ Phits } \\
\hline & & $\mathrm{C} / \mathrm{E}$ & $\sigma_{\mathrm{C} / \mathrm{E}}$ & $\mathrm{C} / \mathbf{E}$ & $\sigma_{\mathrm{C} / \mathrm{E}}$ & $\mathrm{C} / \mathrm{E}$ & $\sigma_{C / E}$ & $\mathrm{C} / \mathrm{E}$ & $\sigma_{\mathrm{C} / \mathrm{E}}$ \\
\hline \multirow{4}{*}{ Mo } & 148 & 1.18 & 0.05 & 1.20 & 0.26 & 1.88 & 0.08 & 1.18 & 0.05 \\
\hline & 320 & 1.11 & 0.05 & 1.13 & 0.27 & 1.40 & 0.07 & 1.08 & 0.05 \\
\hline & 625 & 1.09 & 0.05 & 1.11 & 0.28 & 1.30 & 0.06 & 1.05 & 0.05 \\
\hline & 926 & 1.03 & 0.06 & 1.05 & 0.27 & 1.23 & 0.08 & 0.99 & 0.06 \\
\hline \multirow{4}{*}{$\mathrm{Cu}$} & 172 & 0.78 & 0.08 & 0.78 & 0.11 & 0.89 & 0.09 & 0.90 & 0.09 \\
\hline & 348 & 0.79 & 0.08 & 0.79 & 0.11 & 0.90 & 0.09 & 0.91 & 0.09 \\
\hline & 880 & 0.81 & 0.08 & 0.81 & 0.11 & 0.91 & 0.10 & 0.92 & 0.10 \\
\hline & 1443 & 0.80 & 0.09 & 0.80 & 0.11 & 0.91 & 0.10 & 0.92 & 0.10 \\
\hline \multirow{4}{*}{$\mathrm{Hf}$} & 136 & 0.47 & 0.06 & 0.49 & 0.10 & 4.15 & 0.56 & 0.38 & 0.05 \\
\hline & 318 & 0.35 & 0.05 & 0.41 & 0.10 & 12.30 & 1.77 & 0.58 & 0.08 \\
\hline & 638 & 0.45 & 0.07 & 0.54 & 0.14 & 18.61 & 3.00 & 0.70 & 0.11 \\
\hline & 963 & 0.55 & 0.10 & 0.66 & 0.18 & 25.00 & 4.50 & 0.81 & 0.15 \\
\hline
\end{tabular}

Table 7.(Contd)Summary of the $\mathrm{C} / \mathrm{E}$ values for the FNG cases.

\begin{tabular}{|c|c|c|c|c|c|c|c|c|c|}
\hline \multirow[b]{2}{*}{ Sample } & \multirow[b]{2}{*}{ Cooling time $[\mathrm{s}]$} & \multicolumn{2}{|c|}{ Anita } & \multicolumn{2}{|c|}{ Fispact } & \multicolumn{2}{|c|}{ Fluka } & \multicolumn{2}{|c|}{ Phits } \\
\hline & & $\mathrm{C} / \mathrm{E}$ & $\sigma_{C / E}$ & $\mathrm{C} / \mathrm{E}$ & $\sigma_{C / E}$ & $\mathrm{C} / \mathrm{E}$ & $\sigma_{\mathrm{CIE}}$ & $\mathbf{C} / \mathbf{E}$ & $\sigma_{\mathrm{CIE}}$ \\
\hline \multirow{4}{*}{$\mathrm{Mg}$} & 136 & 0.88 & 0.06 & 0.88 & 0.15 & 0.75 & 0.07 & 0.80 & 0.05 \\
\hline & 316 & 0.92 & 0.11 & 0.92 & 0.34 & 0.79 & 0.09 & 0.89 & 0.10 \\
\hline & 616 & 1.07 & 0.15 & 1.08 & 0.52 & 0.96 & 0.14 & 1.06 & 0.15 \\
\hline & 958 & 1.01 & 0.13 & 1.01 & 0.49 & 0.90 & 0.12 & 0.98 & 0.13 \\
\hline \multirow{4}{*}{$\mathrm{Ni}$} & 139 & 1.68 & 0.36 & 1.68 & 0.54 & 1.54 & 0.33 & 1.47 & 0.32 \\
\hline & 318 & 1.68 & 0.44 & 1.68 & 0.59 & 1.55 & 0.40 & 1.47 & 0.38 \\
\hline & 617 & 1.86 & 0.49 & 1.86 & 0.65 & 1.71 & 0.45 & 1.64 & 0.43 \\
\hline & 918 & 1.94 & 0.58 & 1.94 & 0.72 & 1.78 & 0.54 & 1.73 & 0.52 \\
\hline \multirow{4}{*}{$\mathrm{Cd}$} & 136 & 0.70 & 0.07 & 0.69 & 0.13 & 0.90 & 0.08 & 0.89 & 0.08 \\
\hline & 317 & 0.65 & 0.06 & 0.64 & 0.12 & 0.85 & 0.08 & 0.78 & 0.07 \\
\hline & 618 & 0.61 & 0.05 & 0.60 & 0.11 & 0.80 & 0.06 & 0.70 & 0.06 \\
\hline & 917 & 0.64 & 0.06 & 0.62 & 0.12 & 0.83 & 0.08 & 0.71 & 0.07 \\
\hline \multirow{4}{*}{ Tin } & 137 & 0.81 & 0.07 & 0.83 & 0.12 & 0.99 & 0.09 & 0.89 & 0.08 \\
\hline & 316 & 0.82 & 0.08 & 0.83 & 0.13 & 1.01 & 0.10 & 0.87 & 0.08 \\
\hline & 616 & 0.84 & 0.10 & 0.86 & 0.15 & 1.06 & 0.12 & 0.88 & 0.10 \\
\hline & 917 & 0.83 & 0.12 & 0.84 & 0.16 & 1.05 & 0.15 & 0.85 & 0.12 \\
\hline \multirow{5}{*}{$\mathrm{Re}^{*}$} & 136 & 0.71 & 0.18 & 0.71 & 0.21 & 0.73 & 0.19 & n.a & n.a \\
\hline & 318 & 0.70 & 0.17 & 0.70 & 0.19 & 0.73 & 0.17 & n.a & n.a \\
\hline & 619 & 0.70 & 0.17 & 0.71 & 0.20 & 0.69 & 0.17 & n.a & n.a \\
\hline & 919 & 0.68 & 0.20 & 0.68 & 0.22 & 0.62 & 0.18 & n.a & n.a \\
\hline & 1141 & 0.69 & 0.16 & 0.69 & 0.19 & 0.60 & 0.14 & n.a & n.a \\
\hline \multirow{4}{*}{$\mathrm{Ti}$} & 137 & 0.81 & 0.08 & 0.81 & 0.18 & 0.93 & 0.11 & 0.94 & 0.09 \\
\hline & 317 & 0.79 & 0.08 & 0.79 & 0.11 & 0.97 & 0.10 & 0.94 & 0.09 \\
\hline & 617 & 0.83 & 0.11 & 0.83 & 0.13 & 1.08 & 0.15 & 1.00 & 0.14 \\
\hline & 918 & 0.82 & 0.14 & 0.82 & 0.16 & 1.08 & 0.19 & 0.99 & 0.17 \\
\hline \multirow{5}{*}{ W } & 139 & 0.71 & 0.45 & 0.71 & 0.47 & 0.80 & 0.51 & 0.65 & 0.42 \\
\hline & 320 & 0.74 & 0.43 & 0.74 & 0.45 & 0.83 & 0.48 & 0.69 & 0.40 \\
\hline & 619 & 0.79 & 0.30 & 0.79 & 0.32 & 0.82 & 0.31 & 0.79 & 0.30 \\
\hline & 923 & 0.86 & 0.33 & 0.87 & 0.34 & 0.77 & 0.30 & 0.93 & 0.36 \\
\hline & 1085 & 0.90 & 0.22 & 0.91 & 0.23 & 0.76 & 0.20 & 1.00 & 0.24 \\
\hline \multirow{4}{*}{$\mathrm{Ag}$} & 138 & 0.81 & 0.05 & 0.81 & 0.17 & 0.73 & 0.05 & 0.79 & 0.05 \\
\hline & 319 & 0.81 & 0.04 & 0.81 & 0.17 & 0.77 & 0.04 & 0.78 & 0.04 \\
\hline & 621 & 0.82 & 0.03 & 0.82 & 0.19 & 0.81 & 0.03 & 0.81 & 0.03 \\
\hline & 923 & 0.83 & 0.03 & 0.83 & 0.22 & 0.82 & 0.03 & 0.82 & 0.03 \\
\hline \multirow{4}{*}{ Al_1 } & 138 & 1.01 & 0.04 & 1.01 & 0.10 & 0.93 & 0.05 & 0.92 & 0.03 \\
\hline & 323 & 1.03 & 0.04 & 1.03 & 0.11 & 0.94 & 0.05 & 0.93 & 0.03 \\
\hline & 621 & 1.03 & 0.04 & 1.03 & 0.11 & 0.94 & 0.05 & 0.93 & 0.04 \\
\hline & 922 & 1.03 & 0.04 & 1.03 & 0.11 & 0.95 & 0.05 & 0.94 & 0.04 \\
\hline \multirow{2}{*}{$\mathrm{Al} \_2$} & 4547 & 0.95 & 0.09 & 0.95 & 0.12 & 0.90 & 0.08 & 0.88 & 0.08 \\
\hline & 6324 & 0.94 & 0.09 & 0.94 & 0.13 & 0.90 & 0.09 & 0.87 & 0.08 \\
\hline
\end{tabular}

\section{References}

[1] J. Cetnar, Ann. Nucl. En. 33, issue 7, 640 (2006)

[2] J. C. Sublet, J. Eastwood, G. Morgan, A. Koning, D. Rochman, Progr. in Nucl. Sc. and Tech. 4, 349 (2014)

[3] M. Frisoni, EPJ Web of Conferences 111, 11004 (2016)

[4] T.T. Bohlen, F. Cerutti, M.P.W. Chin, A. Fasso ', A. Ferrari, P.G. Ortega, A. Mairani, P.R. Sala, G. Smirnov, and V. Vlachoudis, Nucl. Data Sheets 120, 211-214 (2014)

[5] A. Ferrari, P.R. Sala, A. Fasso', and J. Ranft, CERN-2005-10 (2005), INFN/TC 05/11, SLAC-R-773

[6] T. Sato, K. Niita, N. Matsuda, S. Hashimoto, Y. Iwamoto, T. Furuta, S. Noda, T. Ogawa, H. Iwase, H. Nakashima, T. Fukahori, K. Okumura, T. Kai, S. Chiba, L. Sihver, Ann. Nucl. Energy 82 (2014)

[7] RJ McConn Jr, CJ Gesh, RT Pagh, RA Rucker, RG Williams III, PNNL-15870 Rev. 1 (2011)

[8] D.G. Cepraga, M. Frisoni, G. Cambi, FUS-TNSA-SE-R-70 Rev. 1 (2003)

[9] Courtesy of M. Frisoni, ENEA, Italya 